\title{
One-Pot Synthesis of Quinazoline Derivatives Using Copper Nanocatalyst Stabilized on Graphene Oxide Functionalized by N1,N2-bis((Pyridine-2- yl)Methyl)Benzene-1,2-Diamine
}

\author{
Alahyar Emami-Nori \\ Bu-Ali Sina University \\ Zahra Karamshahi \\ Bu-Ali Sina University \\ Ramin Ghorbani-Vaghei ( $\sim$ rgvaghei@yahoo.com ) \\ Bu-Ali Sina University
}

\section{Research Article}

Keywords: N-Heterocycle. Quinazoline, Graphene Oxide. Copper Nanocatalyst. N1,N2-Bis((pyridine-2yl)methyl)benzene-1,2-diamine.

Posted Date: November 19th, 2021

DOI: https://doi.org/10.21203/rs.3.rs-1076200/v1

License: (c) (1) This work is licensed under a Creative Commons Attribution 4.0 International License.

Read Full License 


\title{
One-pot Synthesis of Quinazoline Derivatives Using Copper Nanocatalyst Stabilized on Graphene Oxide Functionalized by $N^{1}, N^{2}$-bis ((pyridine-2- yl)methyl)benzene-1,2-diamine
}

\author{
Alahyar Emami-Nori, Zahra Karamshahi, Ramin Ghorbani-Vaghei* \\ Department of Organic Chemistry, Faculty of Chemistry, Bu-Ali Sina University, 65174, Hamadan, Iran. \\ Fax/Tel+98 (811) 8380709; E-mail: rgvaghei@yahoo.com \& ghorbani@basu.ac.ir
}

\begin{abstract}
Having a biological property is just one of features of $N$-heterocycles. Another thing is to be dramatically well-designed. In other words, awe-inspiring combination of materials and the thing that really makes these materials just unique of its kind is nothing but its medical properties. That is why, majority of scientists are full of enthusiasm for synthesizing of these types of materials. In this article, we have reported five effective methods for synthesizing quinazoline, which is a immensely important group of $\mathrm{N}$ heterocycles with using copper nanocatalyst stabilized on graphene oxide functionalized by $N^{1}, N^{2}$-bis((pyridine-2-yl)methyl)benzene-1,2-diamine. Moreover, we have investigated the effects of substitutions connected to aldehydes, benzylamines and benzamides as a carbon source of quinazoline heterocyclic ring. Finally, we have assessed effects kinds of ammonium salts as a nitrogen source of quinazoline heterocyclic ring.

Keywords $N$-Heterocycle. Quinazoline, Graphene Oxide. Copper Nanocatalyst. $N^{1}, N^{2}$ Bis((pyridine-2-yl)methyl)benzene-1,2-diamine.
\end{abstract}

\section{Introduction}

Nowadays, majority of people of all around the world especially undeveloped countries are really suffering from a lack of drug, particularly bacterial medicines. Most of drugs that is used to treat bacterial diseases contain nitrogen-rich heterocyclic rings. This way, designing and discovering novel ways to synthesize these tipes of heterocycles is very essential. Quinazolines are a category of nitrogen-containing heterocyclic compounds, using to treat 
bacterial illnesses. Quinazolines have unique properties. For example, if thiophene is in position 2 of quinazoline structure, which gives to quinazoline the antibacterial property. Moreover, when benzene is in position of 4 , that gives the inhibitory effect of modulating enzyme to quinazoline. But the most significant feature is here, in comparison with others, the simultaneous presence of thiophene and benzene, giving quinazoline both of mentioned properties (Figure 1).

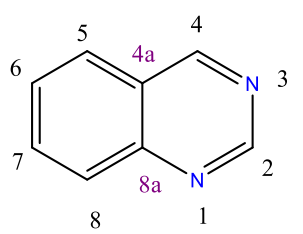

FIGURE 1. The Structure of Quinazoline

Furthermore, the application and frequent presence of structure of qunazoline in immensely important drugs such as Prazosin, Gefitinib and Erlotinib that they are used as an anticancer drug (Figure 2) has led scientists to call this structure pharmaceutical skeleton. As a matter of fact, choosing this name describes the importance of its synthesis [1-10].

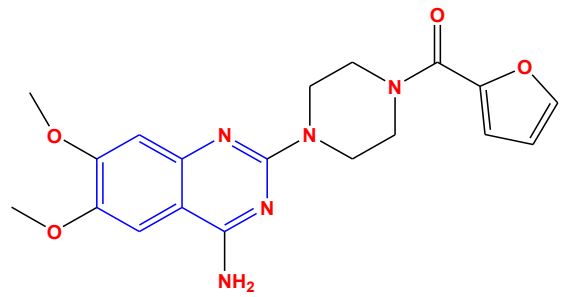

Prazosin<smiles>COc1cc2ncnc(Nc3ccc(F)c(C)c3)c2cc1OCCCN1CCOCC1</smiles>

Gefitinib

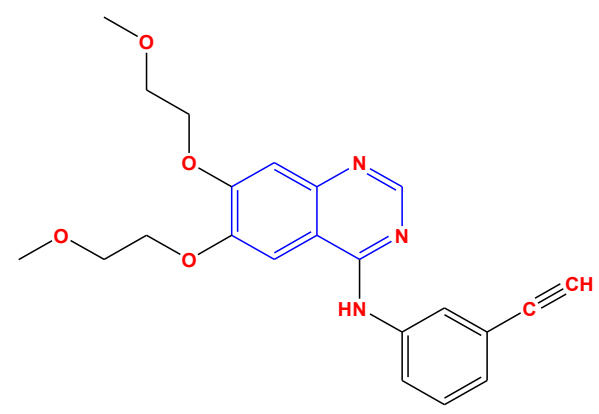

Eriotinib

FIGURE 2. Quinazoline-based drugs 
The fact that presence of catalyst in chemical reaction is important is obvious to all. Not only does it play a crucial role in increasing reaction yield but it also comes with a multitude number of benefits. Such as, decreasing time of reaction, promoting speed and so on. To opt for a catalyst, there are three necessary factors that must be considered. They are simply: green, green and of course green. Because unfortunately nowadays not many people place a high value on environment. The massive burden of protecting the environment is on the shoulders of chemists. Indeed some other options are also worth mentioning such as, high operating speed, high thermal resistance and so on.Trying to accomplish this worthwhile goal has led us to using chemical materials with biological properties. Graphene oxide is a good example of chemical materials with biological property. In other words, it is a green material. Actually, graphene oxide is a three-dimensional platform that destroy bacterias by covalent interaction with them in short time. The use graphene oxide in catalyst synthesis gives us hope that the catalyst's potential contact with the body will not cause any problems $[17,28$, 38].

On the other hand, copper metal has attracted lots of attentions in the past few decades. Probably, this is because of toxicity low or the extraordinary the activities it has shown itself. Such as: the presence of copper in the body is essential to disable tyramine, anomalous diamagnetism behavior, high thermal resistance, biological properties and so on [32, 33, 35].

In this article, we have been able to produce a green catalyst with using a completely green method that have dealt with it in the following.

\section{Experimental}

\section{General Information and Methods}

All commercially available chemicals were purchased from Merck (Kenilworth, NJ) and Fluka (Buchs, Switzerland) companies and used without further purification unless otherwise stated. Infrared (IR) spectroscopy was conducted on a Perkin Elmer GX FT-IR spectrometer. Nuclear magnetic resonance (NMR) spectra were recorded in $\mathrm{CDCl}_{3}$ on Bruker Avance $400 \mathrm{MHz}$ FT spectrometers using tetramethylsilane (TMS) as an internal standard. Chemical shifts were expressed in parts per million ( $\mathrm{ppm})$. Mass spectra were recorded on a Shimadzu QP 1100 BX Mass Spectrometer. Melting points were measured on a BUCHI 510 apparatus in open capillary tubes. Elemental analyses $(\mathrm{C}, \mathrm{H}, \mathrm{N})$ were performed with a $4010 \mathrm{CHNS}-\mathrm{O}$ Analyzer. 
Synthesis of $N^{1}, N^{2}$-bis((pyridine-2-yl)methyl)benzene-1,2-diamine:

A mixture of benzene-1,2-diamine $(6 \mathrm{mmol})$ and pyridine-2-carbaldehyde $(12 \mathrm{mmol})$ was stirred in $25 \mathrm{~mL}$ of dry methanol under $60-80{ }^{\circ} \mathrm{C}$ for $12 \mathrm{~h}$. Then, $24 \mathrm{mmol} \mathrm{NaBH}_{4}$ was added to the reaction. After $12 \mathrm{~h}$ the reaction was completed then the reaction mixture was added 25 $\mathrm{mL}$ chloroform and $25 \mathrm{~mL}$ water. To purify, we created two phases of chloroform and water that product was dissolved in chloroform and impurities were dissolved in water. In this way they were separated each other.

\section{Graphene oxide synthesis by Hummers method:}

A mixture of natural graphite powder $(5 \mathrm{~g})$ and $115 \mathrm{~mL} \mathrm{H}_{2} \mathrm{SO}_{4}(98 \%)$ was stirred for 30 min. Then, $2.5 \mathrm{~g} \mathrm{NaNO}_{3}$ was added to the reaction. To avoid agglomeration, it was stirred strongly. The reaction was transferred to the ice bath. $15 \mathrm{~g}$ of $\mathrm{KMnO}_{4}$ and $50 \mathrm{~mL}$ of $\mathrm{H}_{2} \mathrm{O}_{2}$ $(30 \%)$ were added to reaction. The mixture was stirred for $45 \mathrm{~min}$ and added $10 \mathrm{~mL} \mathrm{HCl}$ (37\%). Finally, separated by centrifugation.

Synthesis of graphene oxide functionalized by $N^{1}, N^{2}$-bis((pyridine-2-yl)methyl)benzene-1,2diamine:

A mixture of $N^{1}, N^{2}$-bis((pyridine-2-yl)methyl)benzene-1,2-diamine (5 mmol) and ammonia ( $50 \mathrm{~mL}$ ) was stirred in $\mathrm{H}_{2} \mathrm{O}$ for $30 \mathrm{~min}$. Then, $2 \mathrm{~g}$ of graphene oxide was added. The reaction was under a condition refluxed for $12 \mathrm{~h}$. Finally, the product was washed with hot water and cold ethanol and transferred under the hood.

Copper immobilization on the graphene oxide functionalized by $N^{1}, N^{2}$-bis((pyridine-2yl)methyl)benzene-1,2-diamine:

A mixture of the graphene oxide functionalized by $N^{1}, N^{2}-b i s(($ pyridine-2yl)methyl)benzene-1,2-diamine $(1 \mathrm{~g})$ and $\mathrm{Cu}\left(\mathrm{CH}_{3} \mathrm{COO}\right)_{2}(0.5 \mathrm{~g})$ was stirred in $\mathrm{EtOH}$ under a condition refluxed for $10 \mathrm{~h}$. Finally, it was washed several time with deionized water.

The typical procedure for the synthesis of 6-chloro-2-(4-(dimethylamino)phenyl)-4phenylquinazoline (Table 7 , entry 1): 
A mixture of 4-(dimethylamino)benzaldehyde $(1 \mathrm{mmol}), 2$-amino-5-chlorobenzophenone $(1 \mathrm{mmol})$, ammonium acetate $(1 \mathrm{mmol})$ and GO@ $N$-Ligand-Cu $(0.003 \mathrm{~g})$ was stirred at $85^{\circ} \mathrm{C}$ for the appropriate time. After completion of the reaction, which was monitored by thin-layer chromatography [acetone/n-hexane (1:6)], the chloroform was added to the reaction mixture and stirred for $10 \mathrm{~min}$. Then added dissolved sodium bicarbonate dissolved. Next, the twophase were separated and the product was obtained by evaporation of chloroform.

The typical procedure for the synthesis of 6-chloro-4-phenyl-2-(3,4,5 trimethoxyphenyl)quinazoline (Table 7 , entry 2):

A mixture of (2-bromo-5-chlorophenyl)(phenyl)methanone (1 mmol), sodium azide (1 mm0l), (3,4,5-trimethoxyphenyl)methanamine $(1 \mathrm{mmol})$ and GO@N-Ligand-Cu (0.002 g) was stirred in DMSO $(5 \mathrm{~mL})$ at $30{ }^{\circ} \mathrm{C}$ for the appropriate time. After completion of the reaction, which was monitored by thin-layer chromatography [acetone/n-hexane (1:6)]. The chloroform was added to the reaction to stir for $10 \mathrm{~min}$. Then, dissolved sodium bicarbonate added. Next, the two-phase were separated and the product was obtained by evaporation of chloroform.

The typical procedure for the synthesis of 6-chloro-4-phenyl-2-(2,4dichlorophenyl)quinazoline (Table 7, entry 10):
A
mixture
of
2,4-dichlorobenzamide
$(1 \mathrm{mmol})$,
(2-bromo-5chlorophenyl)(phenyl)methanamine $(1 \mathrm{mmol}), \mathrm{GO} @ N$-Ligand-Cu $(0.006 \mathrm{~g})$ and $\mathrm{K}_{2} \mathrm{CO}_{3}(0.6$ mmol) was stirred in 2-propanol solvent $(5 \mathrm{~mL})$ at $65{ }^{\circ} \mathrm{C}$ for appropriate time. After completion of the reaction, which was monitored by thin-layer chromatography [acetone/ $n$ hexane (2:7)]. Then, it was purified by the method mentioned in Section 2.7.

The typical procedure for the synthesis of 6-chloro-2-(3-methoxyphenol)-4-phenylquinazoline (Table 7, entry 3):

A mixture of 2-(aminomethyl)-6-methoxyphenol (1 mmol), 2-amino-5cholorobenzophenone $(1 \mathrm{mmol})$ and GO@N-Ligand-Cu $(0.005 \mathrm{~g})$ was stirred under a $\mathrm{O}_{2}$ atomosphere at $50{ }^{\circ} \mathrm{C}$ for the appropriate time. After completion of the reaction, which was monitored by thin-layer chromatography [acetone/ $n$-hexane $(2: 6)]$. Then, it was purified by the method mentioned in Section 2.7. 
The typical procedure for the synthesis of 6-Chloro-2-(furan-2-yl)-4-phenylquinazoline (Table 7, entry 7):

A mixture of furan-2-carbaldehyde (1 mmol), 2-(amino(phenyl)methyl)-4chlorobenzenamine $(1 \mathrm{mmol})$ and GO@ $N$-Ligand-Cu $(0.005 \mathrm{~g})$ was stirred at $75{ }^{\circ} \mathrm{C}$ for the appropriate time. After completion of the reaction, which was monitored by thin-layer chromatography [acetone $/ n$-hexane (2:7)]. Then, it was purified by the method mentioned in Section 2.7.

Typical procedure for the preparation of bis-quinazoline (Scheme 8):

A mixture of 1-(3-phenoxypropoxy)benzaldehayde (1 mmol), 2-amino-5chlorobenzophenone $(2 \mathrm{mmol})$, ammonium acetate $(2 \mathrm{mmol})$ and GO $@ N$-Ligand-Cu $(0.009$ g) was stirred under $85^{\circ} \mathrm{C}$ for the appropriate time. After completion of the reaction, which was monitored by thin-layer chromatography [acetone/toluene/ $n$-hexane (1:2:9)]. Then, it was purified by the method mentioned in Section 2.7.

\section{Results and Discussion}

Our interest in the green design of the catalyst led us to synthesize copper nanocatalyst stabilized on graphene oxide functionalized by $N^{l}, N^{2}$-bis((pyridine-2-yl)methyl)benzene-1,2diamine (Scheme 1) [36].

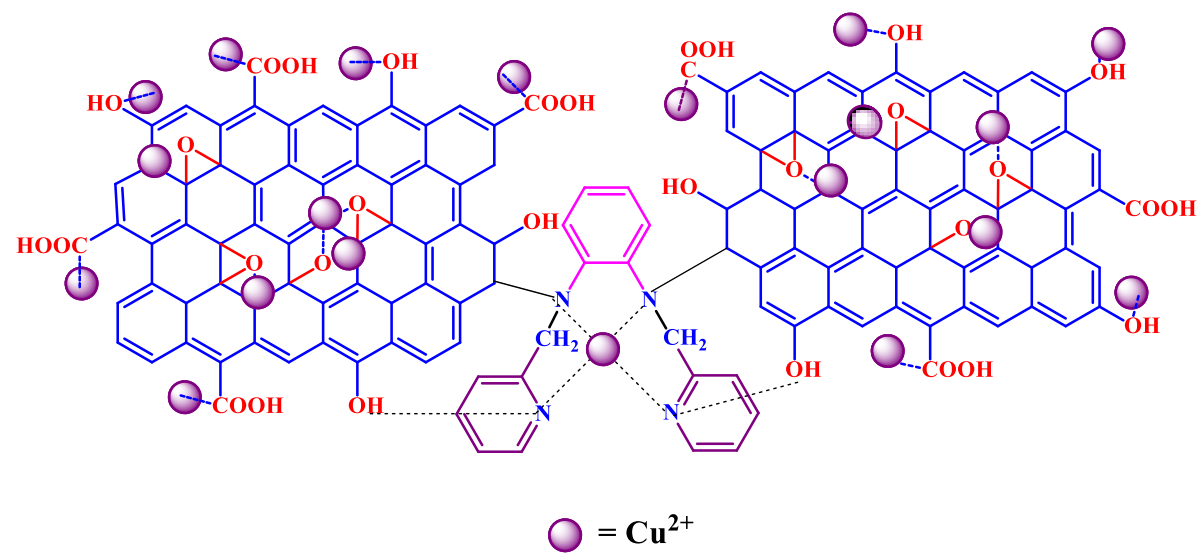


Scheme 1. Copper nanocatalyst stabilized on graphene oxide functionalized by $N^{l}, N^{2}-b i s(($ pyridine- 2yl)methyl)benzene-1,2-diamine (GO@N-Ligand-Cu)

The synthesized GO@N-Ligand-Cu was fully characterized by using various techniques such as FT-IR (Figure 3), Mass Spectroscopy (MS) (Figure 4), ${ }^{1}$ H-NMR (Figure 5), Energydispersive X-ray spectroscopy (EDX) (Figure 6), X-Ray Diffraction (XRD) (Figures 7), Scanning Electron Microscopy (SEM) (Figure 8), DTG and DTA (Figure 9). Figure 3, FT-IR illustrates the different steps of catalyst synthesis, that spectrum a relevant to the synthesis of the $N^{1}, N^{2}$-bis((pyridine-2-yl)methyl)benzene-1,2-diamine compound as the catalyst ligand. In this spectrum, single-branch N-H peak at $3405 \mathrm{~cm}^{-1}$, aromatic C-H peak at $3053 \mathrm{~cm}^{-1}$, aliphatic $\mathrm{CH}_{2}$ peak at $2904 \mathrm{~cm}^{-1}$, and peaks at $1573-1591 \mathrm{~cm}^{-1}$ relevant to $\mathrm{C}=\mathrm{N}$ can be seen. The $\mathrm{b}$ spectrum relevant to graphene oxide as the catalyst substrate includes the broad peak of the $\mathrm{OH}$ acid groups $\mathrm{COOH}$ at $2400-3500 \mathrm{~cm}^{-1}$, the peak of the $\mathrm{C}=\mathrm{O}$ groups $\mathrm{COOH}$ at 1712 $\mathrm{cm}^{-1}$, the peak of the C-O-C group's epoxide at $1167-1229 \mathrm{~cm}^{-1}$, in addition, two peaks at $846 \mathrm{~cm}^{-1}$ and $820 \mathrm{~cm}^{-1}$ also belong to the epoxide groups. Spectrum c relevant to step functionalization of the graphene oxide with $N^{l}, N^{2}$-bis((pyridine-2-yl)methyl)benzene-1,2diamine, which includes the broad peak of the $\mathrm{OH}$ acid groups $\mathrm{COOH}$ at $2400-3500 \mathrm{~cm}^{-1}$, the peak of the $\mathrm{C}=\mathrm{O}$ groups $\mathrm{COOH}$ at $1712 \mathrm{~cm}^{-1}$, the peak of the $\mathrm{C}-\mathrm{O}-\mathrm{C}$ group's epoxide at 1155 $\mathrm{cm}^{-1}$. The results obtained from this FT-IR show success in the synthesis of this compound. The $d$ spectrum corresponds to the last phase of the catalyst synthesis which is after fixation copper, area 2400-3600 has been out of disorder and this indicates the copper coupling with the graphene oxide functional groups. 


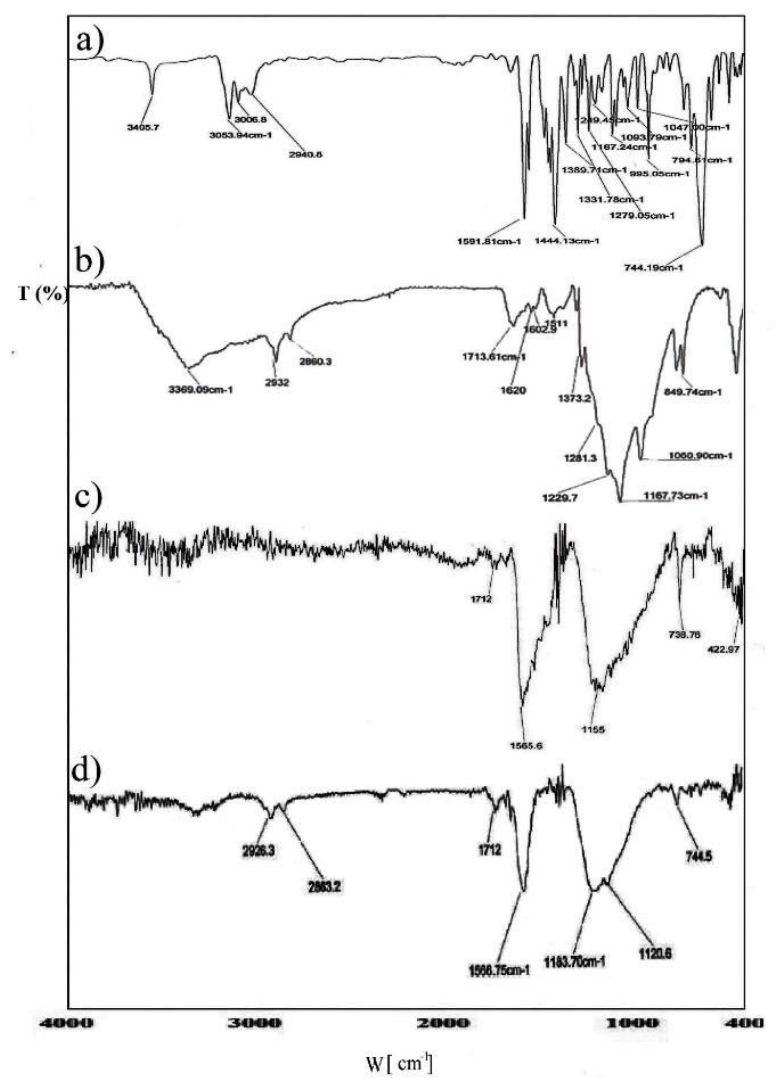

Figure 3. FT-IR spectra of a) $N$-Ligand, b) GO, c) GO@ $N$-Ligand, and d) GO@ $N$-Ligand-Cu

The Mass Spectroscopy of $N^{1}, N^{2}$-bis((pyridine-2-yl)methyl)benzene-1,2-diamine is shown in Figure 4. The presence of molecular ion peak in $290 \mathrm{~m} / \mathrm{z}$ is related to the combination of $N$-Ligand and peaks 78, 91, and $199 \mathrm{~m} / \mathrm{z}$ which are related to cleavages during synthesis.

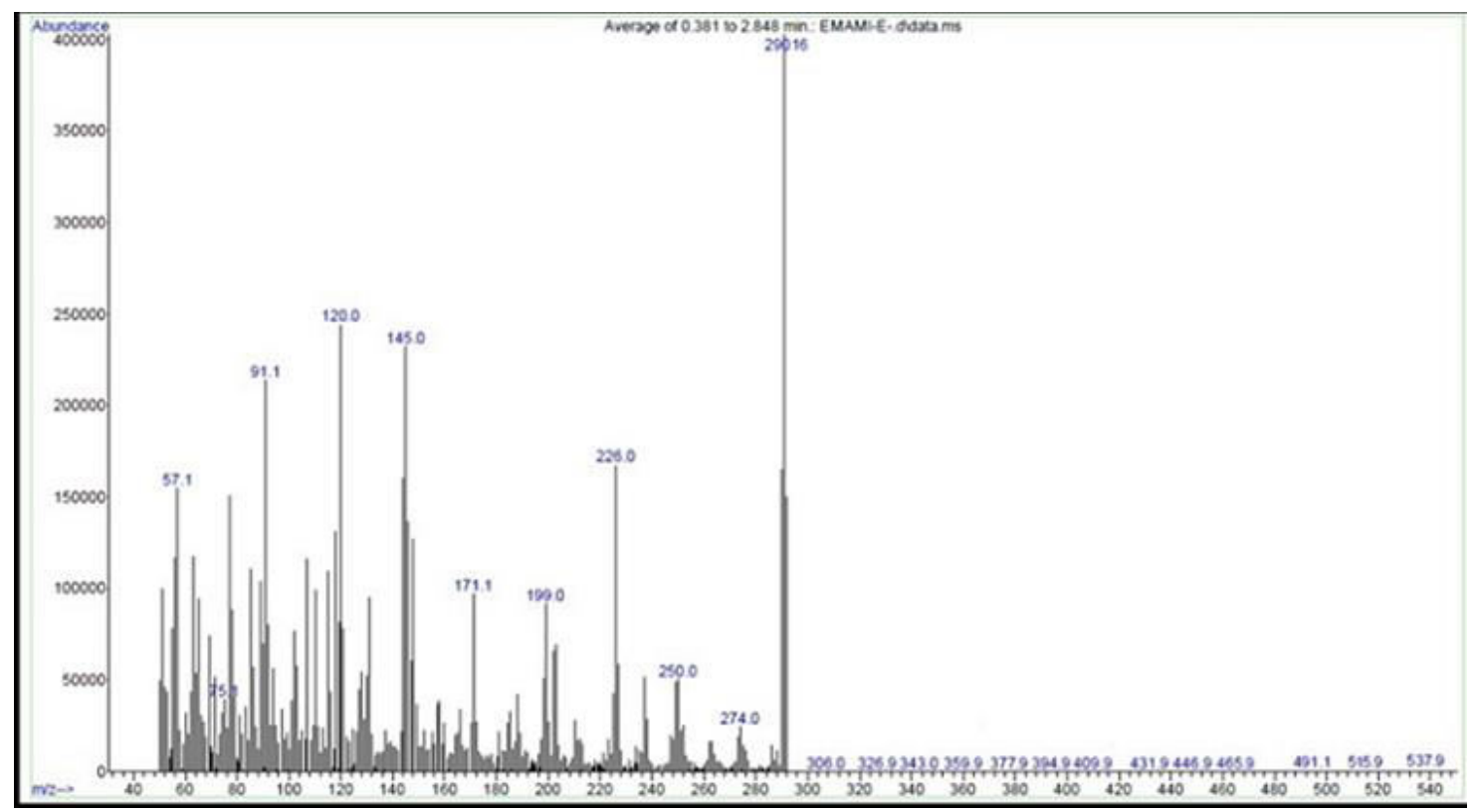

Figure 4. Mass Spectroscopy spectra of $N^{l}, N^{2}$-bis((pyridine-2-yl)methyl)benzene-1,2-diamine ( $N$-Ligand) 
The ${ }^{1} \mathrm{H}-\mathrm{NMR}\left(400 \mathrm{MHz}, \mathrm{CDCl}_{3}\right.$ ) spectra of $\mathrm{N}$-Ligand is performed and investigated (Figure 5). The ${ }^{1} \mathrm{H}-\mathrm{NMR}$ shows N-H peak at $\delta 4.06(\mathrm{~s}, 1 \mathrm{H}), \mathrm{CH}_{2}$ peak at $4.86(\mathrm{~s}, 2 \mathrm{H})$ and other peak related to $\mathrm{C}-\mathrm{H}$ aromatic as follows $6.10-6.12(\mathrm{~m}, 2 \mathrm{H}), 6.19-6.21(\mathrm{~m}, 2 \mathrm{H}), 6.52-$ 6.53( t, 2H), 6.67-6.69 (d, 2H), 6.87-6.69 (t, 2H) and 7.41-7.42 (d, 2H).

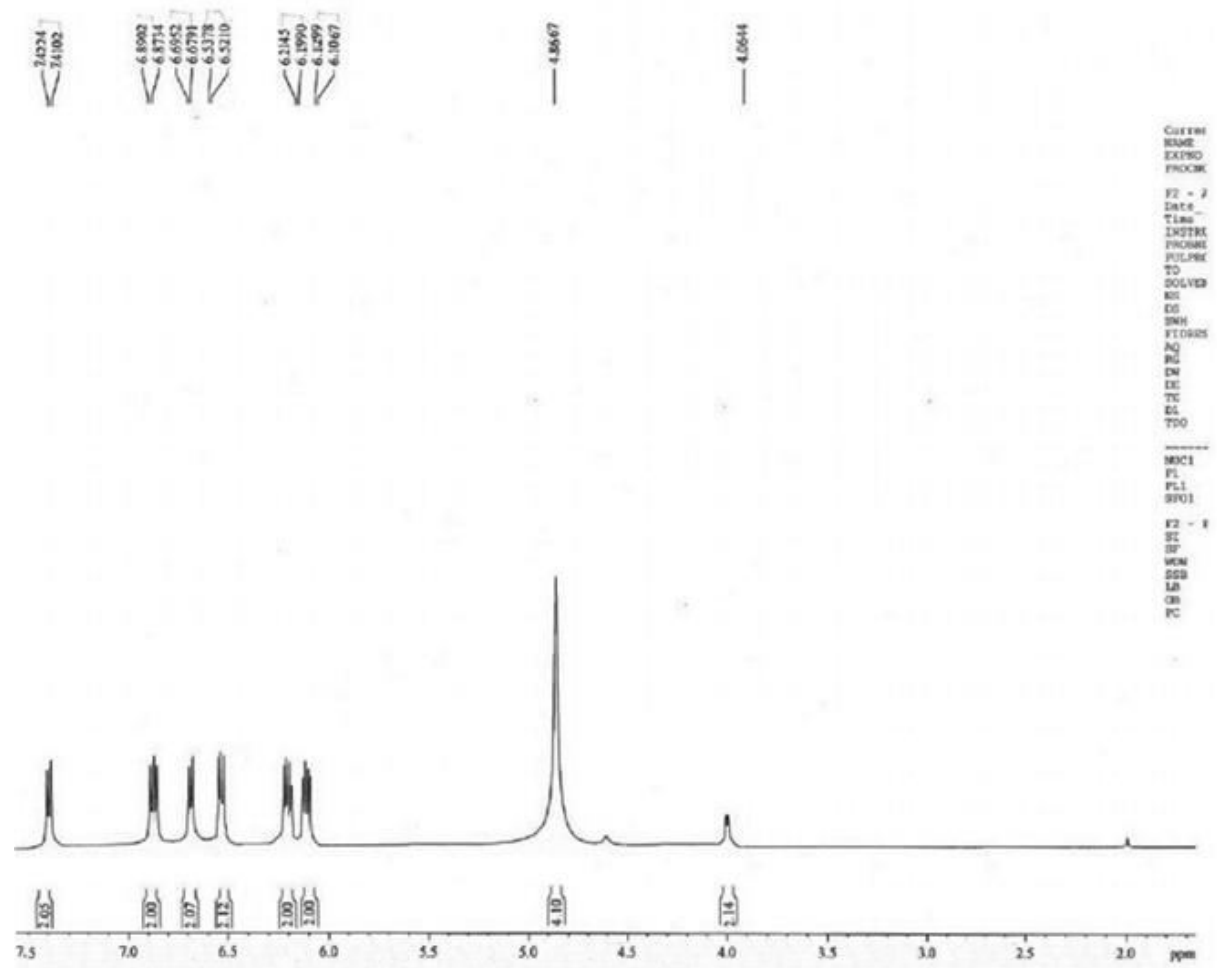

Figure 5. ${ }^{1} \mathrm{H}$-NMR of $N^{l}, N^{2}$-bis((pyridine-2-yl)methyl)benzene-1,2-diamine ( $N$-Ligand)

The elements present in the catalyst were investigated using the EDX technique (Figure 6). In this spectrum, $\mathrm{O}, \mathrm{N}, \mathrm{Cu}, \mathrm{C}$ peaks were observed corresponding to the compounds of graphene oxide, $N^{l}, N^{2}$-bis((pyridine-2-yl)methyl)benzene-1,2-diamine, copper, graphene oxide and $N^{l}, N^{2}$-bis((pyridine-2-yl)methyl)benzene-1,2-diamine. 


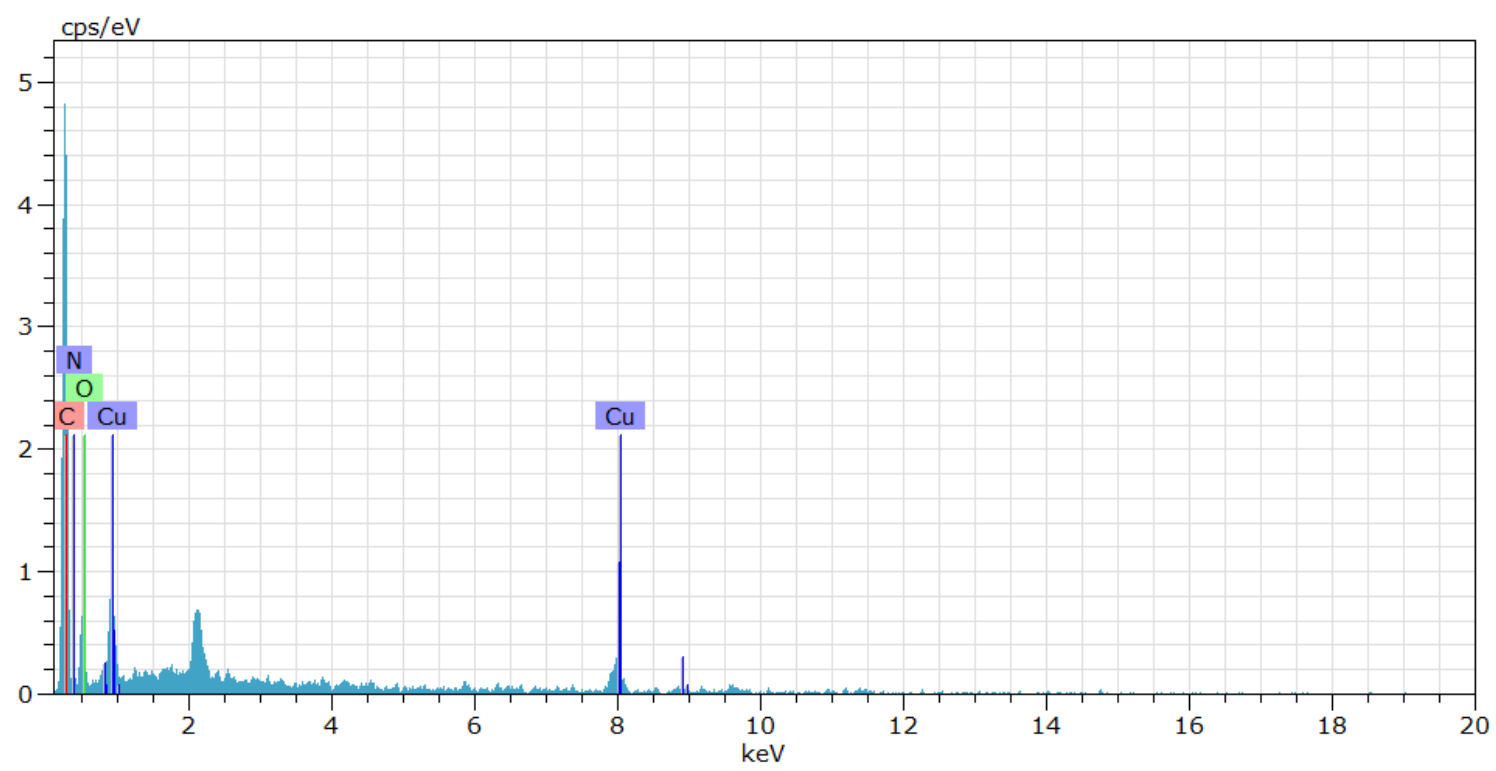

Figure 6. EDX of GO@ $N$-Ligand-Cu

In XRD and SEM techniques, the size, shape and morphology of the catalyst were investigated. XRD relevant to graphene (spectrum a) and nanocatalyst (spectrum b) were investigated in Figure 7 and in the range of $2-90^{\circ}$. In spectrum, two peaks appear at $2 \theta=25^{\circ}$, $45^{\circ}$ corresponding to 100 and 200 graphene oxide crystal plates. In spectrum b, five peak numbers with values of $25^{\circ}, 35^{\circ}, 43^{\circ}, 55^{\circ}, 72^{\circ}$ are seen that $25^{\circ}$ and $35^{\circ}$ peak corresponds to the graphene oxide and the $43^{\circ}, 55^{\circ}$ and $72^{\circ}$ peak, relevant to the copper metal. In addition, the intensity of the peaks is weaker than of GO, indicating connecting copper to graphene oxide but the crystalline structure of graphene oxide remains. 


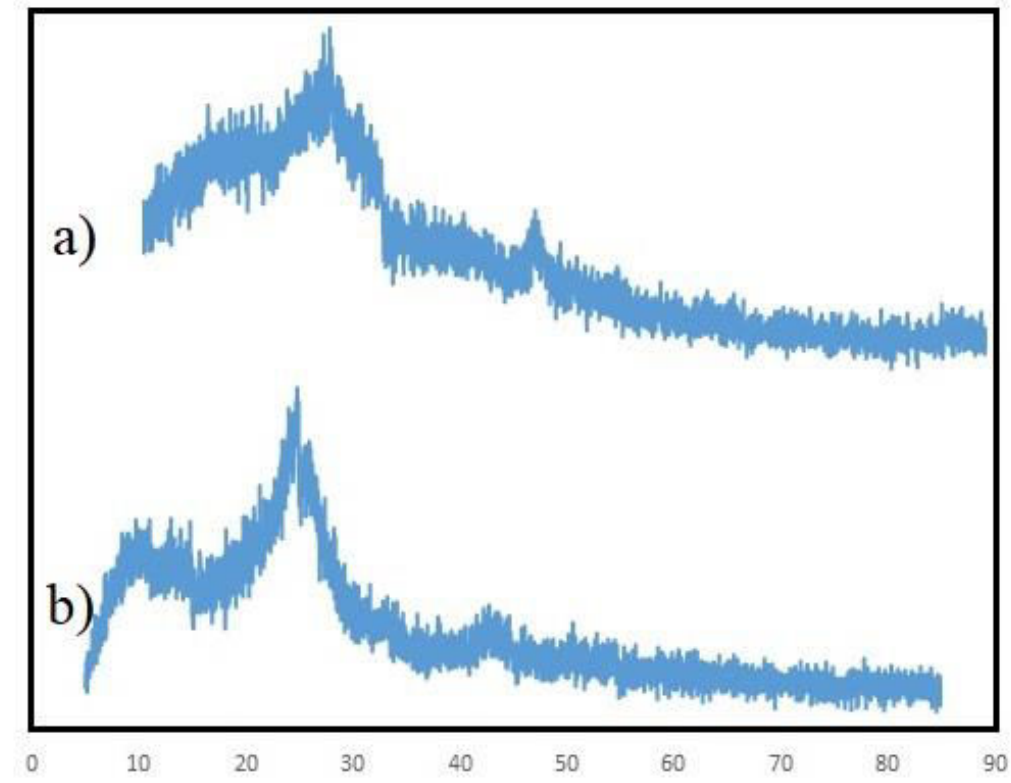

Figure 7. XRD of a) GO and b) GO@N-Ligand-Cu

In another investigation, the scanning electron microscope (SEM) micrographs of the catalyst showed that the particles have not completely agglomerated. Moreover, particles of the catalyst were observed on a nanoscale (Figure 8).

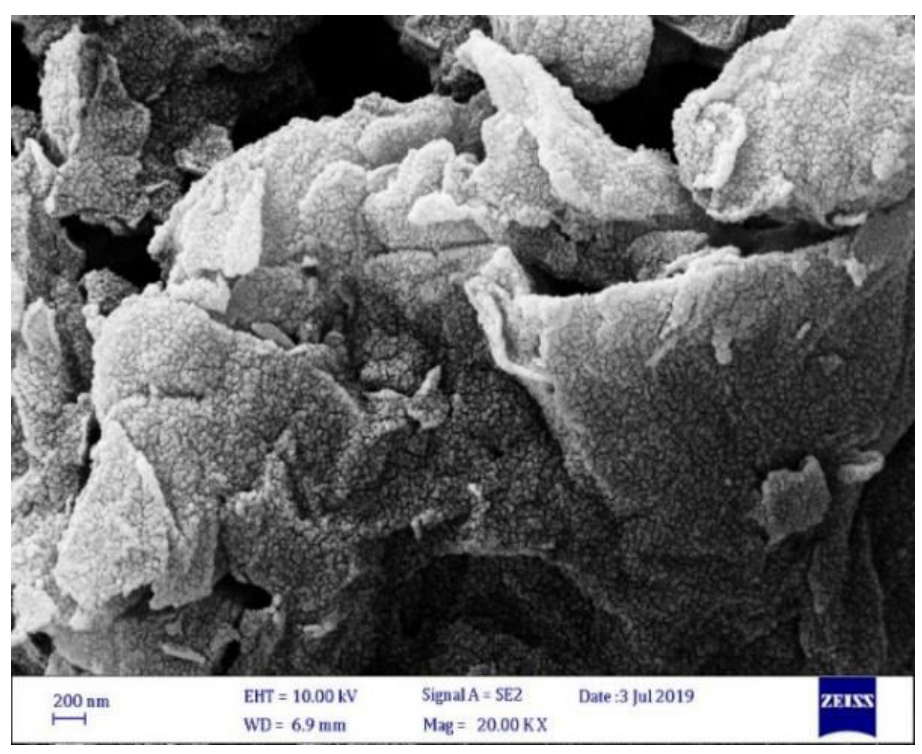

Figure 8. SEM of GO@ $N$-Ligand-Cu

Derivative thermal gravimetric (DTG) and differential thermal (DTA) of GO@N-Ligand$\mathrm{Cu}$ was also investigated (Figure 9). Several degeneration stages observed for catalyst in the DTA pattern. The first weight loss is seen at $65^{\circ} \mathrm{C}$, which is estimated to be due to methanol solvent evaporation. The second weight loss occurs at temperatures of 90-100 ${ }^{\circ} \mathrm{C}$, which may 
be related to the evaporation of ethanol and water solvents. The third weight loss is observed at 325 to $320{ }^{\circ} \mathrm{C}$, which is related to the degradation of the $N^{l}, N^{2}-b i s(($ pyridine-2yl)methyl)benzene-1,2-diamine compound and the graphene oxidized functional groups and the rest of the catalyst residues are degraded at the fourth weight loss at $410-500{ }^{\circ} \mathrm{C}$. The obtained results indicate that the catalyst can be used up to $300{ }^{\circ} \mathrm{C}$.

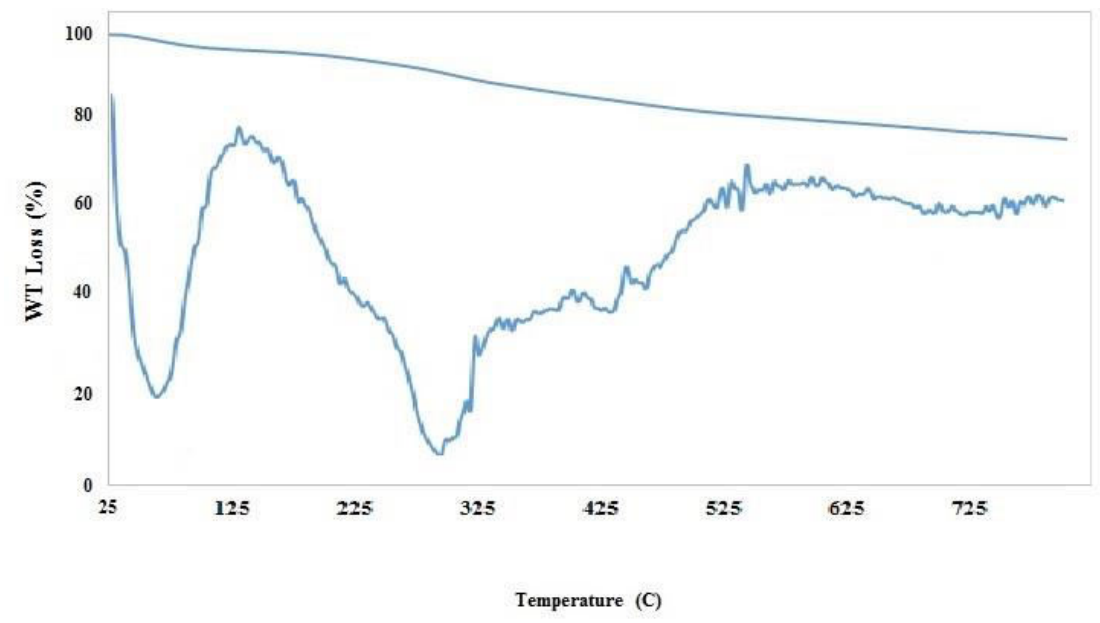

Figure 9. DTA and TGA of GO@ $N$-Ligand-Cu

After the synthesis and full characterization of GO@N-Ligand-Cu, the catalyst was used to synthesize $N$-heterocycles compounds such as quinazolines and bis-quinazoline which will be discussed in the following.

\section{History}

In 1869 Griess prepared the first quinazoline derivative, 2-cyano-3,4-dihydro-4oxoquinazoline, by the reaction of cyanogens with anthranilic acid. The bicyclic product was called bicyanoamido benzoyl and used this name until 1885 [13]. The preparation of the quinazoline came many years later when Bischler and Lang obtained it by decarboxylation of the 2-carboxy derivative. A more satisfactory synthesis of quinazoline was subsequently devised by Gabriel in 1903. The name was proposed by Widdege. Other names such as phenmiazine, benzyleneamidine, benzo-1,3-diazine, 5,6-benzopyrimidine, and 1,3diazanapthaline have occasionally been used [13-17]. In recent years, different strategies have been proposed for the synthesis of quinazoline. In 2015, Ghorbani-Vaghei et al. the quinazoline derivatives were synthesized using TBBDA and PBBS catalysts [8]. Deshmukh et al. in 2018 were able to synthesize quinazoline derivatives using benzylamine, ammonium 
acetate and 2-aminobenzylalcohol [2]. The presence of a fused benzene ring alters the properties of the pyrimidine ring considerably. The two nitrogen atoms are not equivalent, and the marked polarization of the 3,4-double bond is reflected in the reactions of quinazoline. The properties of substitute quinazolines depend largely on the nature of the substituents, whether they are in the pyrimidine ring or in the benzene ring, and whether or not complete conjugation is present in the pyrimidine ring [17]. In this paper, five green and efficient methods for the synthesis of quinazoline using two-component reactions and tricomponent reactions in the presence of GO@N-Ligand-Cu as a useful catalyst are reported (Scheme 2).

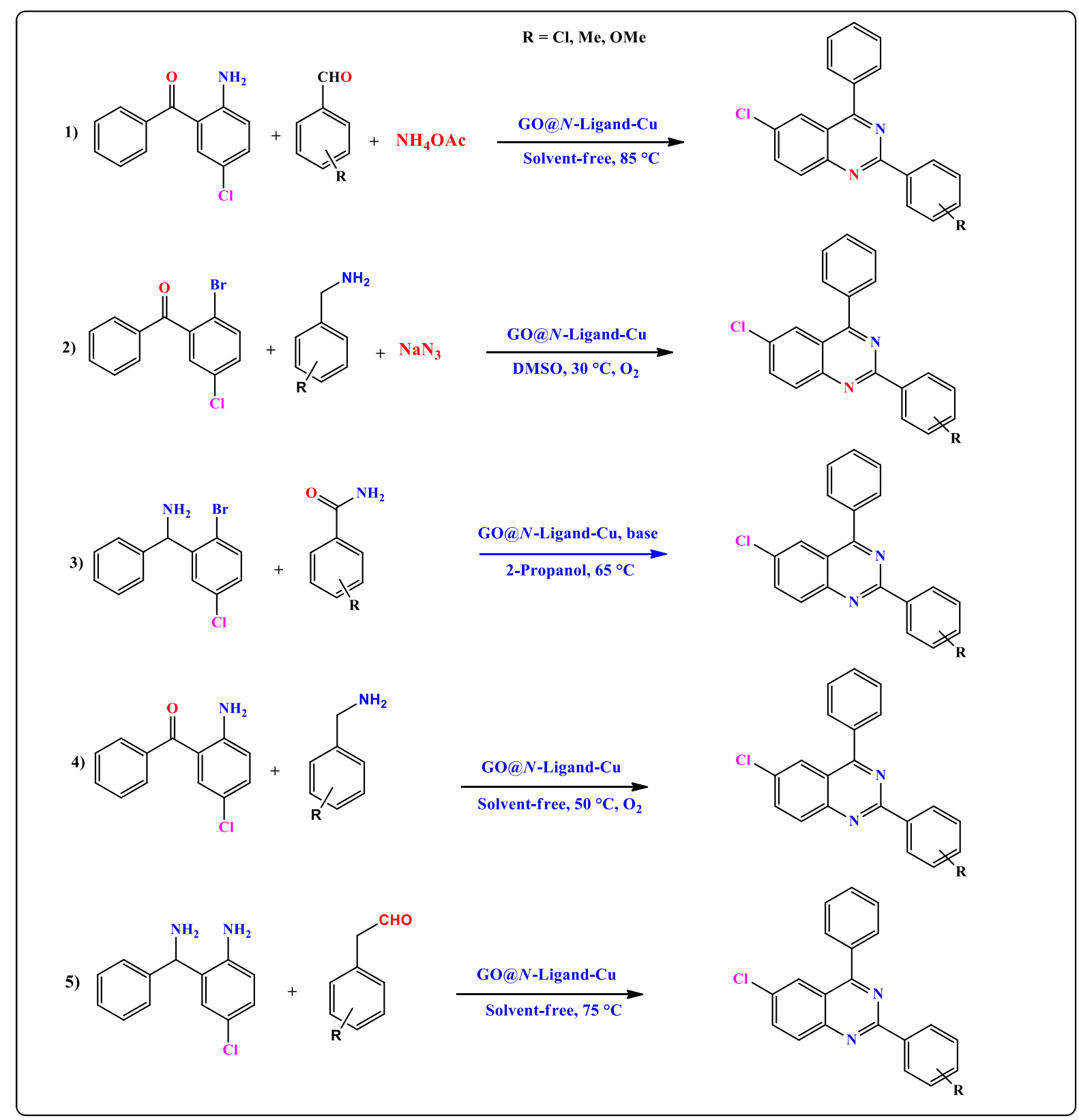

scheme 2. Synthesis of quinazoline derivatives 
As the first part of our research in organic synthesis catalyzed by GO@N-Ligand-Cu, we report an efficient and green strategy for the synthesis of quinazoline via tri-component reaction and one-pot from 2-amino-5-cholorobenzophenone, ammonium salts and aldehyde derivatives under a solvent-free condition at $85{ }^{\circ} \mathrm{C}$ (Scheme 2, reaction 1). Initial efforts have been focused on optimizing a condition for the synthesis 6-chloro-2-(4(dimethylamino)phenyl)-4-phenylquinazoline of 4-(dimethylamino)benzaldehyde, 2-amino5-cholorobenzophenone and ammonium acetate as a model reaction under different conditions. We investigated kinds of solvents and a solvent-free condition with a wide variety of temperatures and different amounts of catalyst for the model reaction. The results showed that $0.003 \mathrm{~g}$ of GO@ $N$-Ligand-Cu catalyst under a solvent-free condition at $85{ }^{\circ} \mathrm{C}$ could have the highest reaction rate and highest product yield (Table 1, entry 1, $12 \mathrm{~min}, 91 \%$,).

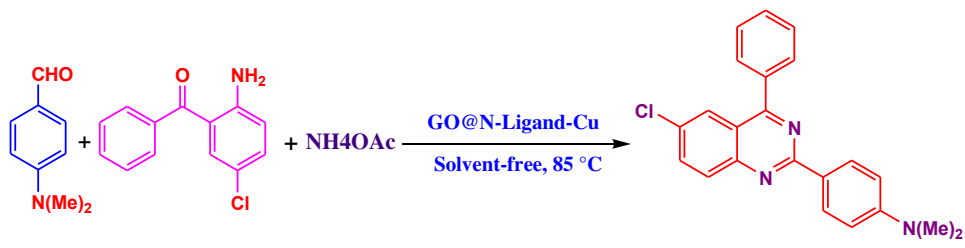

Table 1. Reaction time and yield in different conditions

\begin{tabular}{|c|c|c|c|c|c|}
\hline Entery & Solvent & $\begin{array}{c}\text { Amount of catalyst } \\
{[\text { GO@N-Ligand-Cu (g)] }}\end{array}$ & Temperature $\left({ }^{\circ} \mathbf{C}\right)$ & $\begin{array}{l}\text { Time } \\
(\min )\end{array}$ & Yield $(\%)^{b}$ \\
\hline 1 & Solvent-free & 0.003 & 85 & 12 & 91 \\
\hline 2 & Solvent-free & 0.001 & 85 & 55 & 79 \\
\hline 3 & Solvent-free & 0.004 & 85 & 25 & 67 \\
\hline 4 & Solvent-free & 0.005 & 85 & 33 & 60 \\
\hline 5 & Solvent-free & 0.006 & 85 & 35 & 55 \\
\hline 6 & Solvent-free & 0.007 & 85 & 60 & 43 \\
\hline 7 & Solvent-free & 0.008 & 85 & 21 & 40 \\
\hline 8 & Solvent-free & 0.006 & 95 & 21 & 87 \\
\hline 9 & Solvent-free & 0.006 & 105 & 25 & 83 \\
\hline 10 & Solvent-free & 0.006 & 75 & 18 & 85 \\
\hline 11 & Solvent-free & 0.006 & 65 & 60 & 54 \\
\hline 12 & Solvent-free & 0.006 & 55 & 180 & 47 \\
\hline 13 & $\mathrm{C}_{2} \mathrm{H}_{5} \mathrm{OH}$ & 0.006 & 90 & 480 & 32 \\
\hline 14 & $\mathrm{H}_{2} \mathrm{O}$ & 0.006 & 100 & 430 & 30 \\
\hline 15 & $\mathrm{C}_{2} \mathrm{H}_{5} \mathrm{OH} / \mathrm{H}_{2} \mathrm{O}$ & 0.006 & 95 & 540 & 33 \\
\hline 16 & $\mathrm{CHCl}_{3}$ & 0.006 & 67 & 540 & 47 \\
\hline
\end{tabular}




\begin{tabular}{rccccc}
\hline \hline 17 & $\mathrm{CH}_{3} \mathrm{COCH}_{3}$ & 0.006 & 50 & 540 & 32 \\
18 & $\mathrm{C}_{6} \mathrm{H}_{5} \mathrm{Cl}$ & 0.006 & 120 & 300 & 87 \\
19 & $\mathrm{C}_{6} \mathrm{H}_{5} \mathrm{I}$ & 0.006 & 120 & 300 & 43 \\
20 & $\mathrm{C}_{4} \mathrm{H}_{8} \mathrm{O}_{2}$ & 0.006 & 85 & 600 & 10 \\
21 & $\mathrm{C}_{6} \mathrm{H}_{5} \mathrm{CH}_{3}$ & 0.006 & 110 & 1440 & 5 \\
\hline
\end{tabular}

a Reaction condition: 4-(dimethylamino)benzaldehyde (1 mmol), 2-amino-5-cholorobenzophenone (1 mmol) and ammonium acetate $(1 \mathrm{mmol}), 85^{\circ} \mathrm{C}$ and GO@N-Ligand-Cu $(0.003)$ (Reaction 1, scheme 2). ${ }^{\mathrm{b}}$ Isolated yield.

To determine the scope and generality of this protocol, we examined the types of ammonium salts as a nitrogen source and the types of aldehydes as a carbon source. Under a optimum condition, several ammonium halides were tested $\left(\mathrm{NH}_{4} \mathrm{X}, \mathrm{X}=\mathrm{I}, \mathrm{Br}, \mathrm{Cl}\right)$ which among them ammonium iodide had the best yield while the ammonium bromide had little yield. Seems to the larger volume of iodide causes crystal defect and makes it easier to break or since iodide has less electronegativity than bromide, it settles negative charge less quickly gains ammonium's protons. Then, ammonium acetate was used. The reaction yield was increased in the presence of ammonium acetate (Table 2, entry 5). That may be related to the amount of energy needed to separate ammonia from the salt system or due to the production of stable acetic acid from ammonium acetate, the $\mathrm{pH}$ of the system decreases and the presence of $\mathrm{H}^{+}$in the reaction medium activates the carbonyl group.

$$
\mathrm{CH}_{3} \mathrm{COOH} \rightleftharpoons \mathrm{H}^{+}+\mathrm{CH}_{3} \mathrm{COO}^{-}
$$

The use of ammonium acetate in the reaction was prefered to other ones due to its high efficiency, low toxicity and easy separation.

Table 2. Optimizatin of the reaction condition ${ }^{\mathrm{a}}$

\begin{tabular}{ccc}
\hline \hline Entry & $* \mathbf{N}^{*}$ & Yield (\%) \\
\hline 1 & $\mathrm{NH}_{4} \mathrm{I}$ & 68 \\
\hline 2 & $\mathrm{NH}_{4} \mathrm{Br}$ & Trace \\
\hline 3 & $\mathrm{NH}_{4} \mathrm{Cl}$ & Trace \\
\hline 4 & $\mathrm{NH}_{4} \mathrm{HCO}_{3}$ & 5 \\
\hline 5 & $\mathrm{NH}_{4} \mathrm{OAc}$ & 91 \\
\hline
\end{tabular}

a Reaction Condition: 4-(dimethylamino)benzaldehyde (1 mmol), 2-amino-5-cholorobenzophenone (1 mmol) and ammonium acetate $(1 \mathrm{mmol}), 85^{\circ} \mathrm{C}$ and GO@N-Ligand-Cu $(0.003 \mathrm{~g})$. 
In another study, the effect and positions of electron releasing substituents and electronwithdrawing substituents attached to the aldehydes were investigated as carbon source. The highest yield was obtained as the electron releasing substituents were attached to the aldehyde in the para position (Table 4, entries 1 and 4, reaction 1). The reaction yield was relatively high in the ortho position (Table 4, entry12, reaction 1). Of course, the ortho positions may be due to spatial hindrance, that is less yield than the para position. As the substitutions were in the meta positions, it had no effect on reaction efficiency (Table 4, entries 5 and 13, reaction 1). However, substitutions of electron-withdrawing in para and ortho positions did not any affect on the efficiency of reaction (Table 4, entries 6 and 10). The reaction yield is reduced if they are in the meta position (Table 4, entry 9, reaction 1). In scheme 3 we propose a mechanism for the conversion of 2-amino-5-chlorobenzophenone, ammonium acetate and aldehyde to quinazoline. 


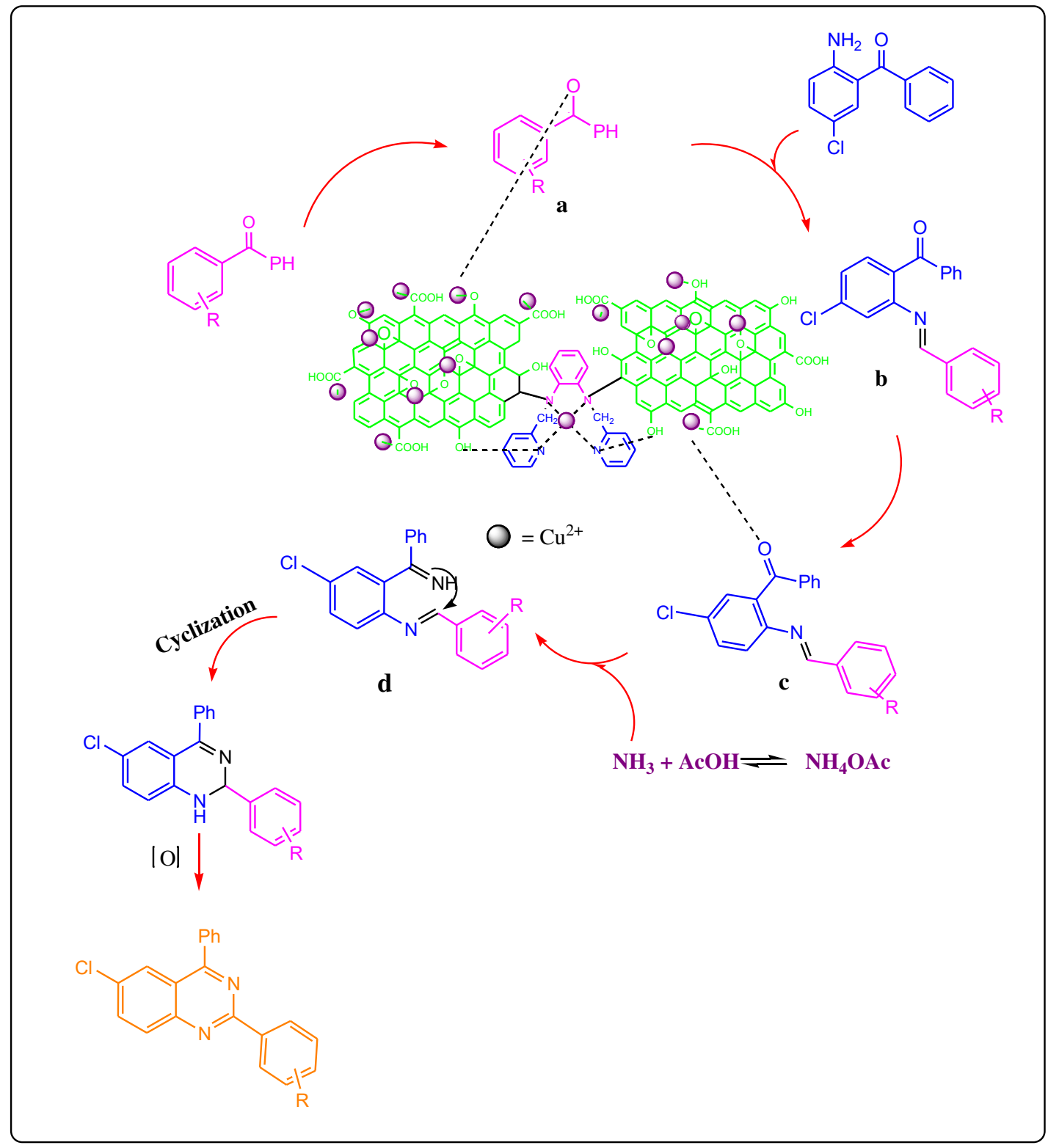

Scheme 3. Proposed mechanism for the synthesis quinazoline by the use of GO@ $N$-Ligand-Cu via method 1 (Reaction 1 in Scheme 2)

According to this mechanism, GO@N-Ligand-Cu nanocatalyst act as Lewis acid, and by recieving the electron pair of the carbonyl aldehyde group activates it, that gives the formation of the intermediate compound $\mathbf{a}$. Then, by the entrance of amine, the intermediate compound $\mathrm{b}$ is formed. In contination, the catalyst activates the carbonyl group intermediate b, and forms the intermediate c. In the next step, by the attack of ammonia to the activated carbonyl formed intermediated $\mathbf{d}$, which by an intramolecular reaction and oxidation is formed the quinazoline [8]. 
Another advantage of this catalyst is to reuse. After completion of the reaction, by adding $10 \mathrm{~mL}$ of chloroform to the reaction mixture, the catalyst was separated from the product that it was used after washing and drying in the reaction model. Copper nanocatalyst can be used five times in a row without losing of activity (Figure 10).

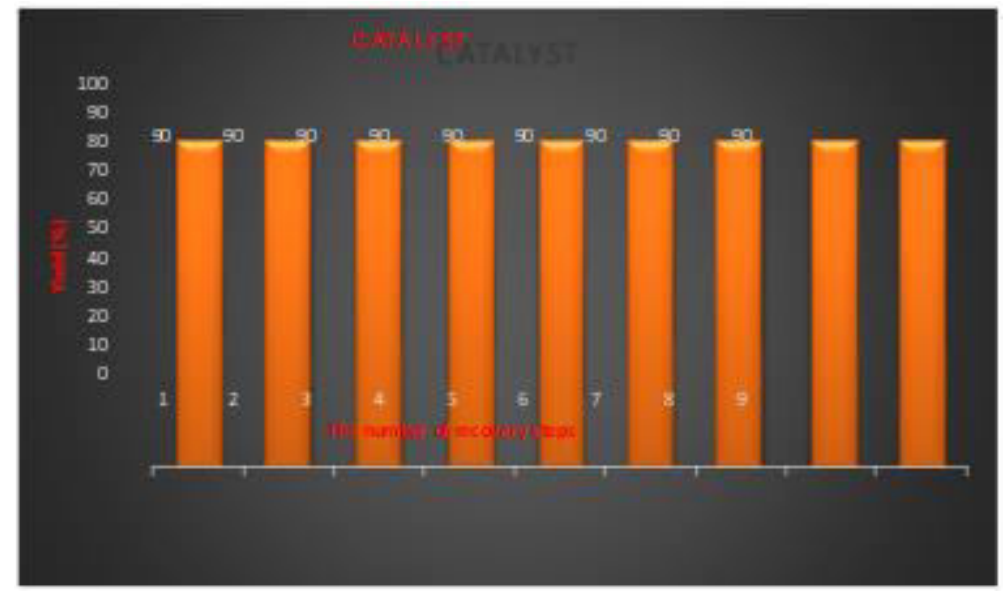

Figure 10. Recyling and reuse of atalyst GO@N-Ligand-Cu

As the second part of our research in this paper, in another efficient strategy, we were able to synthesize quinazoline derivatives via a tri-component reaction of (2-bromo-5chlorophenyl)(phenyl)methanone, benzylamine derivatives and sodium azide (Scheme 2, reaction 2). Initially, the reaction of (2-bromo-5-chlorophenyl)(phenyl)methanone, sodium azide and (3,4,5-trimethoxyphenyl)methanamine was evaluated as a simple model substrate in the presence of solvents, a solvent-free condition, at a wide variety of temperatures, different amounts of $\mathrm{GO} @ N$-Ligand-Cu catalyst under different atmosphere conditions to reaction optimization. It was found the reaction is completed in DMSO solvent after 14 min at $30{ }^{\circ} \mathrm{C}$ under $\mathrm{O} 2 \mathrm{a}$ atmosphere and $0.002 \mathrm{~g}$ of the catalyst with a $94 \%$ yield (Tbale 3 ). 


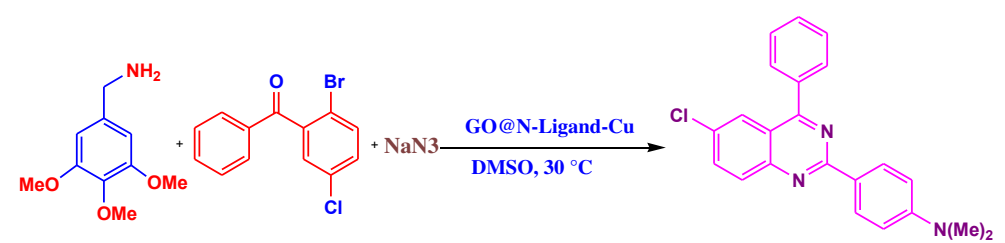

Table 3. Reaction time and yield in different conditions ${ }^{\mathrm{a}}$.

\begin{tabular}{|c|c|c|c|c|c|}
\hline Entery & Solvent & $\begin{array}{c}\text { Amount of catalyst } \\
{[\text { GO@N-Ligand-Cu (g)] }}\end{array}$ & Temperature $\left({ }^{\circ} \mathbf{C}\right)$ & $\begin{array}{l}\text { Time } \\
(\min )\end{array}$ & Yield $(\%)^{b}$ \\
\hline 1 & DMSO & 0.002 & 30 & 14 & 94 \\
\hline 2 & DMSO & 0.002 & 40 & 14 & 93 \\
\hline 3 & DMSO & רחת & 50 & 14 & 93 \\
\hline 4 & DMSO & & 60 & 16 & 92 \\
\hline 5 & DMSO & 0.002 & 75 & 20 & 89 \\
\hline 6 & DMSO & 0.002 & 100 & 35 & 70 \\
\hline 7 & DMSO & 0.004 & 30 & 15 & 85 \\
\hline 8 & DMSO & 0.006 & 30 & 19 & 60 \\
\hline 9 & DMSO & 0.008 & 30 & 45 & 47 \\
\hline 10 & Chlorobenzene & & 30 & 14 & 87 \\
\hline 11 & Iodobenzene & 0.002 & 30 & 55 & 40 \\
\hline 12 & Toluene & 0.002 & 30 & $5(\mathrm{~h})$ & 30 \\
\hline 13 & $\mathrm{EtOH}$ & 0.002 & 30 & $2(\mathrm{~h})$ & 54 \\
\hline 14 & $\mathrm{H}_{2} \mathrm{O}$ & 0.002 & 30 & $3(h)$ & 58 \\
\hline 15 & $\mathrm{EtOH} / \mathrm{H}_{2} \mathrm{O}$ & 0.002 & 30 & $3(\mathrm{~h})$ & 73 \\
\hline 16 & Chloroform & $0 \Omega 0$ & 30 & $6(\mathrm{~h})$ & 23 \\
\hline 17 & Acetone & & 30 & $4(\mathrm{~h})$ & 45 \\
\hline 18 & Ethyl acetate & 0.002 & 30 & $10(\mathrm{~h})$ & 16 \\
\hline 19 & DMSO & 0.002 & 30 & $10(\mathrm{~h} 0$ & trace \\
\hline
\end{tabular}

aReaction conditions: (2-bromo-5-chlorophenyl)(phenyl)methanone (1 mmmol), sodium azide( $1 \mathrm{mmmol})$ and (3,4,5-trimethoxyphenyl)methanamine $(1 \mathrm{mmmol}), 30^{\circ} \mathrm{C}, \mathrm{GO} @ \mathrm{~N}-\mathrm{Ligand}-\mathrm{Cu}(0.002)$ and under $\mathrm{O}_{2}$ atmosphere (Reaction 2 , scheme ). ${ }^{\mathbf{b}}$ Isolated yield. ${ }^{\mathrm{c}}$ Under nitrogen atmosphere

Then, we examined the effect of substituents attached to benzylamine. It was found benzylamines containing electron releasing substituents in the para position had the highest yield (Table 4 , entry 2, reaction 2). It may be due to their resonance state at the ring formation stage that it helps protons exit radically. Furthermore, benzyls containing electronwithdrawing substituents were tested too. Electron-withdrawing substituents in the meta position results in lower reaction yield but other situations (para and ortho) had a little impact on reaction yield (Compare entry 9 with entries 10 and 16 in Table 4, reaction 2). 
Table 4. Synthesis of quinazoline derivatives in the presence of GO@N-Ligand-Cu

\begin{tabular}{|c|c|c|c|c|c|c|}
\hline & Product & Reaction1 & Reaction2 & Reaction3 & Reaction4 & Reaction5 \\
\hline Entry & M.p & $\begin{array}{l}\text { Time } \\
(\min ) \\
\text { \& Yield }(\%)\end{array}$ & $\begin{array}{l}\text { Time } \\
(\min ) \\
\text { \&Yield }(\%)\end{array}$ & $\begin{array}{l}\text { Time } \\
(\min ) \\
\text { \& Yield }(\%)\end{array}$ & $\begin{array}{l}\text { Time } \\
(\min ) \\
\text { \&Yield }(\%)\end{array}$ & $\begin{array}{l}\text { Time } \\
(\min ) \\
\text { \&Yield }(\%)\end{array}$ \\
\hline 1 & & $12 / 91$ & $31 / 89$ & $170 / 57$ & $22 / 89$ & $40 / 90$ \\
\hline
\end{tabular}

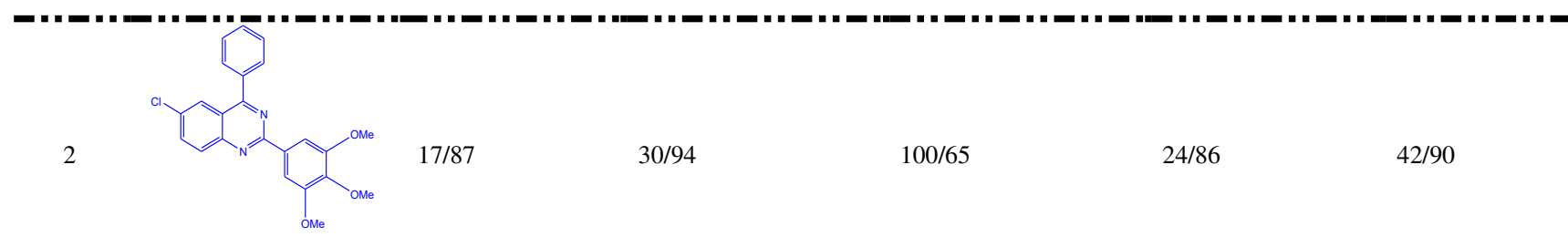

164-166

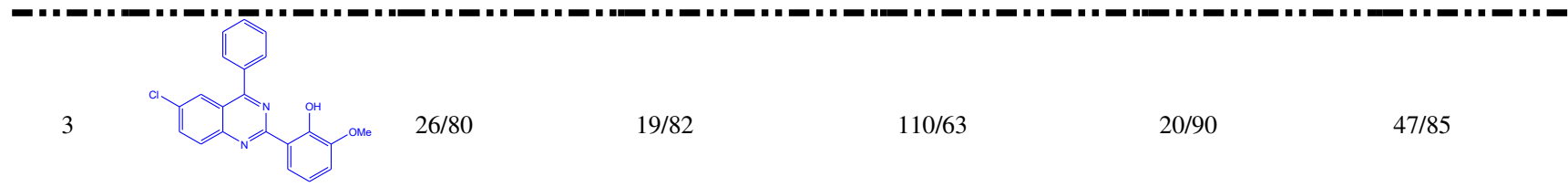

249-251

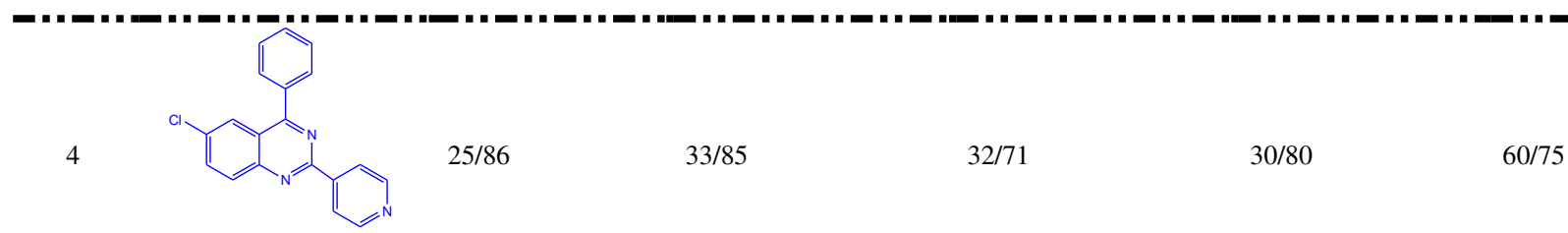

190-191
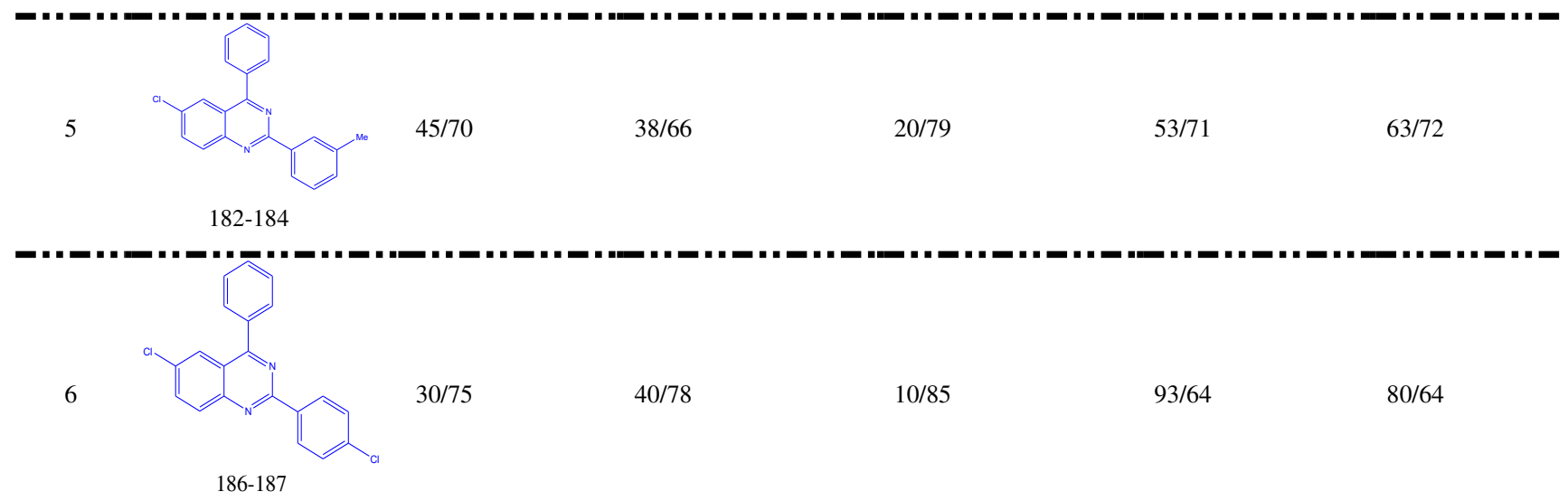


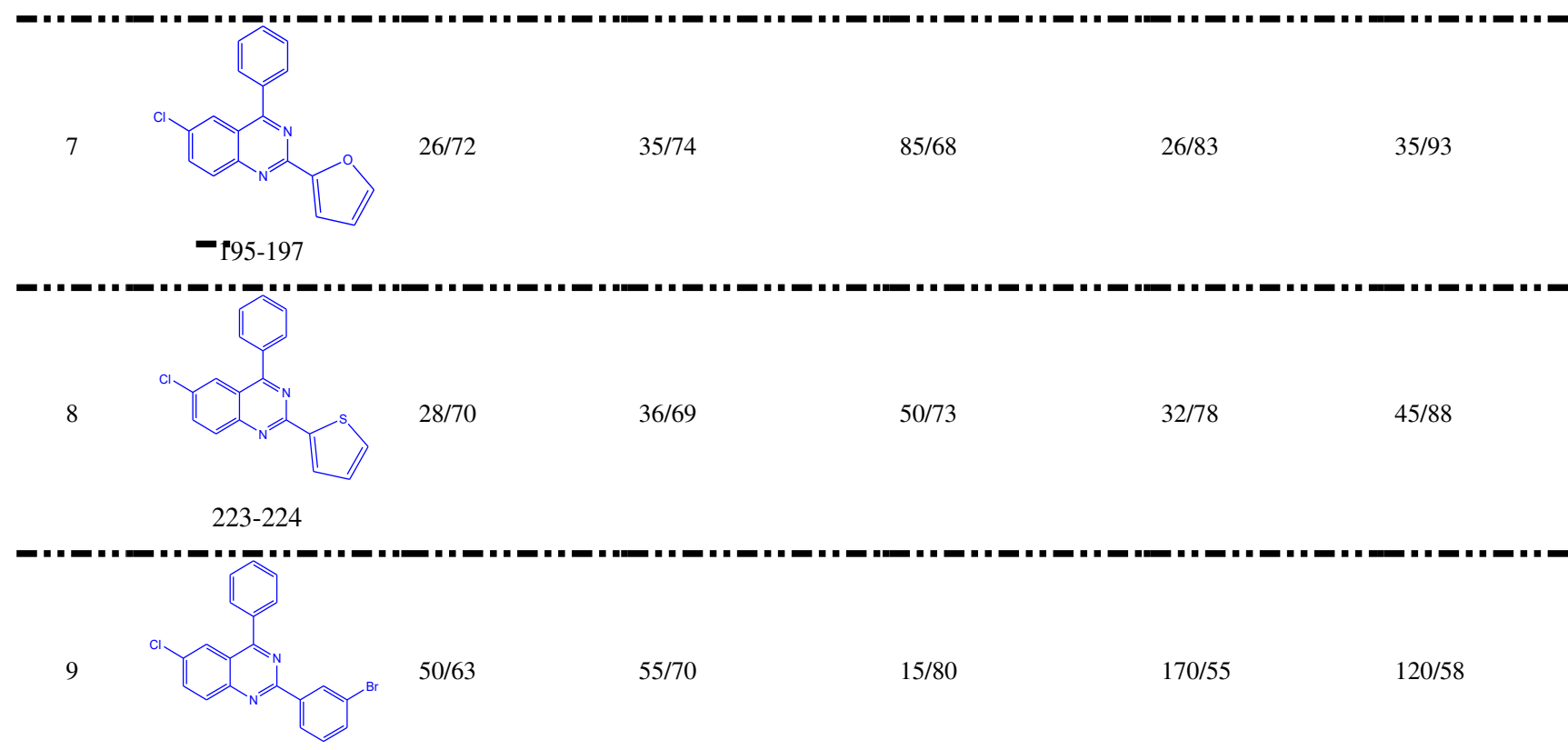

178-180

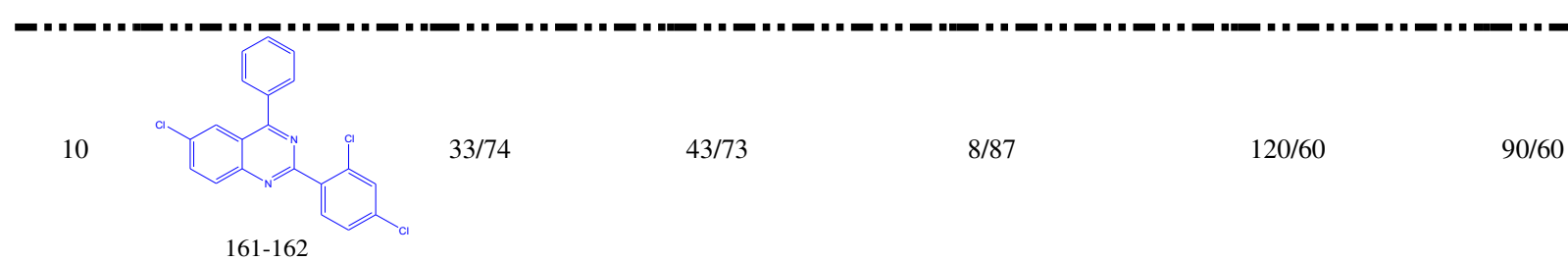

$161-162$

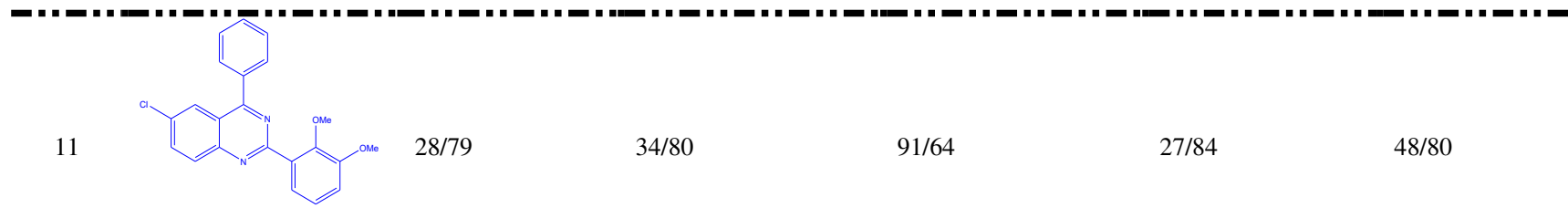

156-158
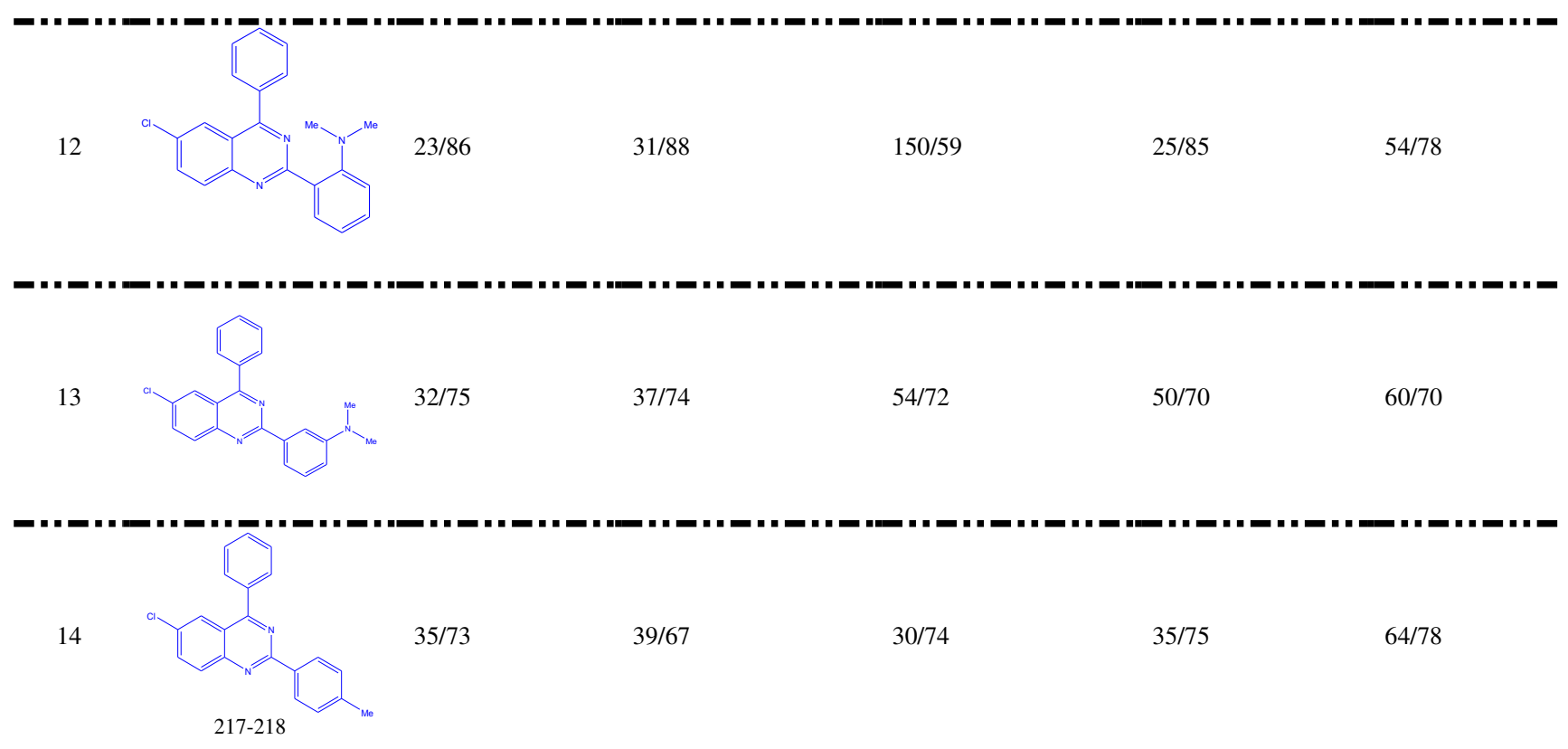

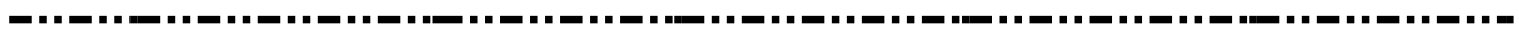




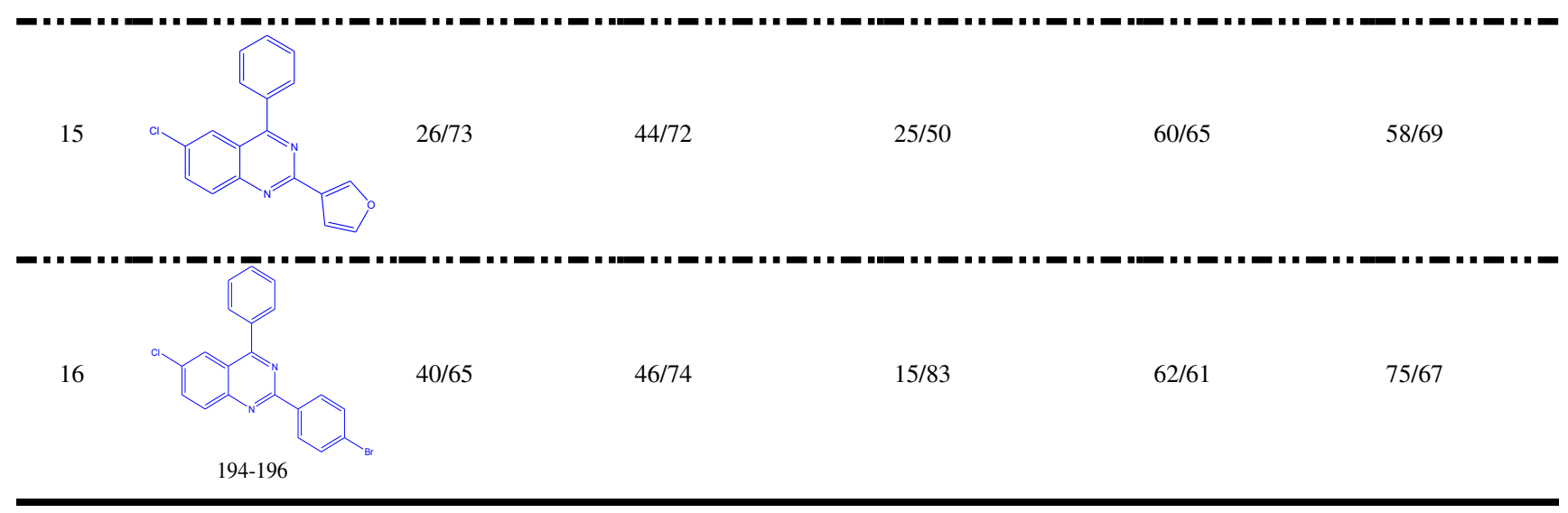

The proposed mechanism to the synthesis of quinazoline derivatives by the use of (2bromo-5-chlorophenyl)(phenyl)methanone, sodium azide and benzylamine derivatives in the presence of GO@N-Ligand-Cu is illustrated in Scheme 4.

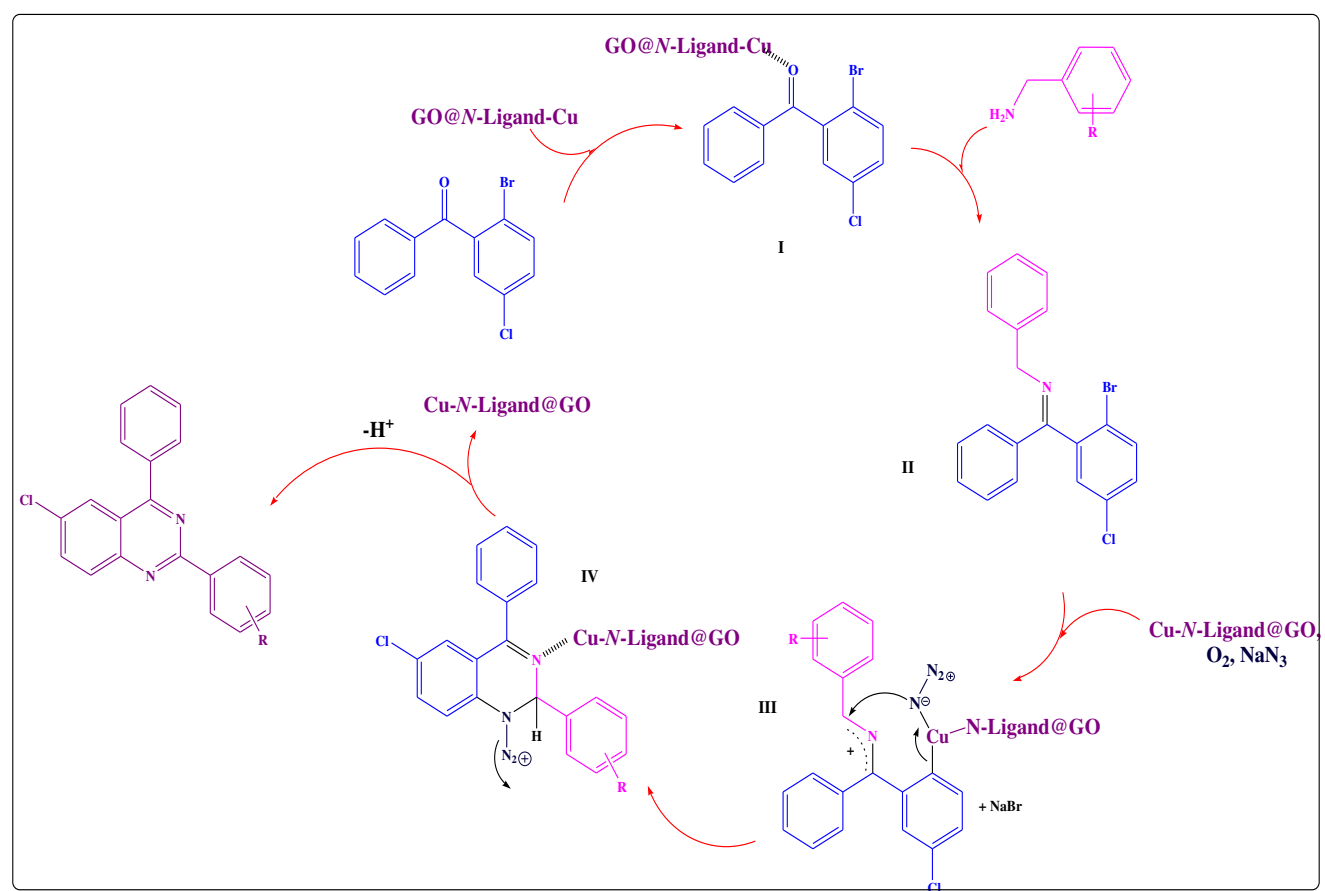

Scheme 4. Proposed mechanism for the synthesis quinazoline by the use of GO@N-Ligand-Cu via method 2 (Reaction 2 in Scheme 2)

Firestly, carbonyl is activated by GO@N-Ligand-Cu and intermediate (I) is formed. By the arrival of benzylamine and the loss of one molecule of water, intermediate (II) is formed. By acidic proton exit radically in the presence of atmospheric oxygen, radical ions are created. Then, by the entry of sodium azide and copper coupling, intermediate (III) is formed. In the next step, by the use of cyclization, loss of $\mathrm{N}_{2}$, and $\mathrm{H}^{+}$from IV, the product is produced [37]. 
Our interest in quinazoline synthesis via different methods led us to synthesize quinazoline by the use of another useful method (Scheme 2, reaction 3). Based on this method, quinazoline was obtained via a two-component reaction and one-pot of benzamide derivatives and (2-bromo-5-chlorophenyl)(phenyl)methanamine. In order to obtain a optimal condition, reaction of 2,4-dichlorobenzamide and (2-bromo-5chlorophenyl)(phenyl)methanamine were investigated as a model reaction at a wide variety of temperatures, types of solvents, different amount of catalyst and different bases. After doing experiments, it was found to increase yield to $87 \%$ in the presence of $0.006 \mathrm{~g}$ of GO@N-Ligand-Cu, 2-propanol solvent and $\mathrm{K}_{2} \mathrm{CO}_{3}(0.06 \mathrm{mmol})$ (Table 5, entry 1). Therefore, $0.006 \mathrm{~g}$ of nanocatalyst was sufficient to complete the reaction, of course a higher amount of catalyst does not increase yield (Table 5, entries 18, 19 and 20). Investigation of various solvents, such as, EtOH, DMSO, DMF, $\mathrm{H}_{2} \mathrm{O}$, iodobenzene and chlorobenzene in the presence of $0.006 \mathrm{~g}$ of catalyst at a temperature range of $50-115^{\circ} \mathrm{C}$ showed these solvents reverse the reaction and decrease yield of reaction $(6 \mathrm{~h} \& 50 \%, 5 \mathrm{~h} \& 35 \%, 10 \mathrm{~h} \& 28 \%, 4 \mathrm{~h}$

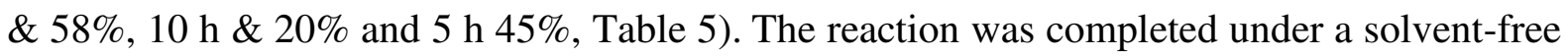
condition at $24 \mathrm{~h}$ with a $9 \%$ yield (Table 5 , entry 21 ).

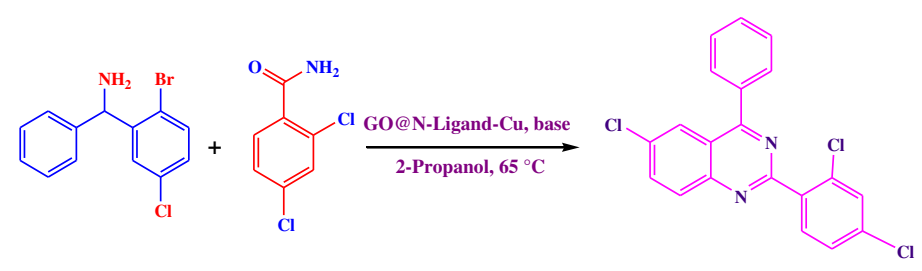

Table 5. Reaction time and yield in various conditions ${ }^{\mathrm{a}}$.

\begin{tabular}{cccccc}
\hline \hline Entery & Solvent & $\begin{array}{c}\text { Amount of catalyst } \\
{[\mathbf{G O} @ N \text {-Ligand-Cu }(\mathbf{g})]}\end{array}$ & Temperature $\left({ }^{\circ} \mathbf{C}\right)$ & Base & Yield $(\%)$ (Time $(\mathbf{m i n})$ \\
\hline 1 & 2-Propanol & 0.006 & 65 & $\mathrm{~K}_{2} \mathrm{CO}_{3}$ & $87 / 8$ \\
2 & 2-Propanol & 0.006 & 50 & $\mathrm{~K}_{2} \mathrm{CO}_{3}$ & $67 / 30$ \\
3 & 2-Propanol & 0.006 & 75 & $\mathrm{~K}_{2} \mathrm{CO}_{3}$ & $73 / 20$ \\
4 & 2-Propanol & 0.006 & 95 & $\mathrm{~K}_{2} \mathrm{CO}_{3}$ & $69 / 25$ \\
5 & 2-Propanol & 0.006 & 115 & $\mathrm{~K}_{2} \mathrm{CO}_{3}$ & $68 / 30$ \\
6 & DMSO & 0.006 & 65 & $\mathrm{~K}_{2} \mathrm{CO}_{3}$ & $35 / 5(\mathrm{~h})$ \\
\hline
\end{tabular}




\begin{tabular}{cccccc}
\hline 7 & DMF & 0.006 & 65 & $\mathrm{~K}_{2} \mathrm{CO}_{3}$ & $28 / 10(\mathrm{~h})$ \\
8 & $\mathrm{EtOH}$ & 0.006 & 65 & $\mathrm{~K}_{2} \mathrm{CO}_{3}$ & $50 / 6(\mathrm{~h})$ \\
9 & $\mathrm{H} \mathrm{O}_{2}$ & 65 & $\mathrm{~K}_{2} \mathrm{CO}_{3}$ & $58 / 4(\mathrm{~h})$ \\
10 & $\mathrm{H}{ }_{2} \mathrm{O} / \mathrm{EtOH}$ & 0.006 & 65 & $\mathrm{~K}_{2} \mathrm{CO}_{3}$ & $70 / 2(\mathrm{~h})$ \\
11 & 2-Propanol & 0.006 & 65 & $\mathrm{~K}_{3} \mathrm{PO}_{4}$ & $46 / 1(\mathrm{~h})$ \\
12 & 2-Propanol & 0.006 & 65 & $\mathrm{Cs}_{2} \mathrm{CO}_{3}$ & $15 / 4(\mathrm{~h})$ \\
13 & Chlorobenzene & 0.006 & 65 & $\mathrm{~K}_{2} \mathrm{CO}_{3}$ & $45 / 5(\mathrm{~h})$ \\
14 & Iodobenzene & 0.006 & 65 & $\mathrm{~K}_{2} \mathrm{CO}_{3}$ & $20 / 10(\mathrm{~h})$ \\
15 & 2-Propanol & 0.002 & 65 & $\mathrm{~K}_{2} \mathrm{CO}_{3}$ & $37 / 35$ \\
16 & 2-Propanol & 0.003 & 65 & $\mathrm{~K}_{2} \mathrm{CO}_{3}$ & $49 / 30$ \\
17 & 2-Propanol & 0.005 & 65 & $\mathrm{~K}_{2} \mathrm{CO}_{3}$ & $70 / 15$ \\
18 & 2-Propanol & 0.007 & 65 & $\mathrm{~K}_{2} \mathrm{CO}_{3}$ & $68 / 20$ \\
19 & 2-Propanol & 0.008 & 65 & $\mathrm{~K}_{2} \mathrm{CO}_{3}$ & $59 / 30$ \\
21 & 2-Propanol & 0.009 & $\mathrm{~K}_{2} \mathrm{CO}_{3}$ & $37 / 1(\mathrm{~h})$ \\
21 & Solvent-free & 0.006 & $\mathrm{~K}_{2} \mathrm{CO}_{3}$ & $9 / 24(\mathrm{~h})$ \\
\hline
\end{tabular}

${ }^{a}$ Reaction condition: 2,4-dichlorobenzamide (1 mmol) and (2-bromo-5-chlorophenyl)(phenyl)methanamine (1 mmol), $65{ }^{\circ} \mathrm{C}, \mathrm{GO} @ N$-Ligand-Cu $(0.006 \mathrm{~g})$ and $\mathrm{K}_{2} \mathrm{CO}_{3}(0.6 \mathrm{mmol})$ (Reaction 3, scheme 2). ${ }^{\mathrm{b}}$ Isolated yield.

After optimizing the condition, different amides were used. Although amides containing electron-withdrawing substituents at para and ortho positions increased the reaction yield (Table 4, entries 6, 10 and 16, reaction 3), electron releasing substituents reduced the reaction yields (Table 4, entries 1 and 2). The results are summarized in Table 4. Scheme 5 presents a proposed mechanism for quinazoline synthesis. 


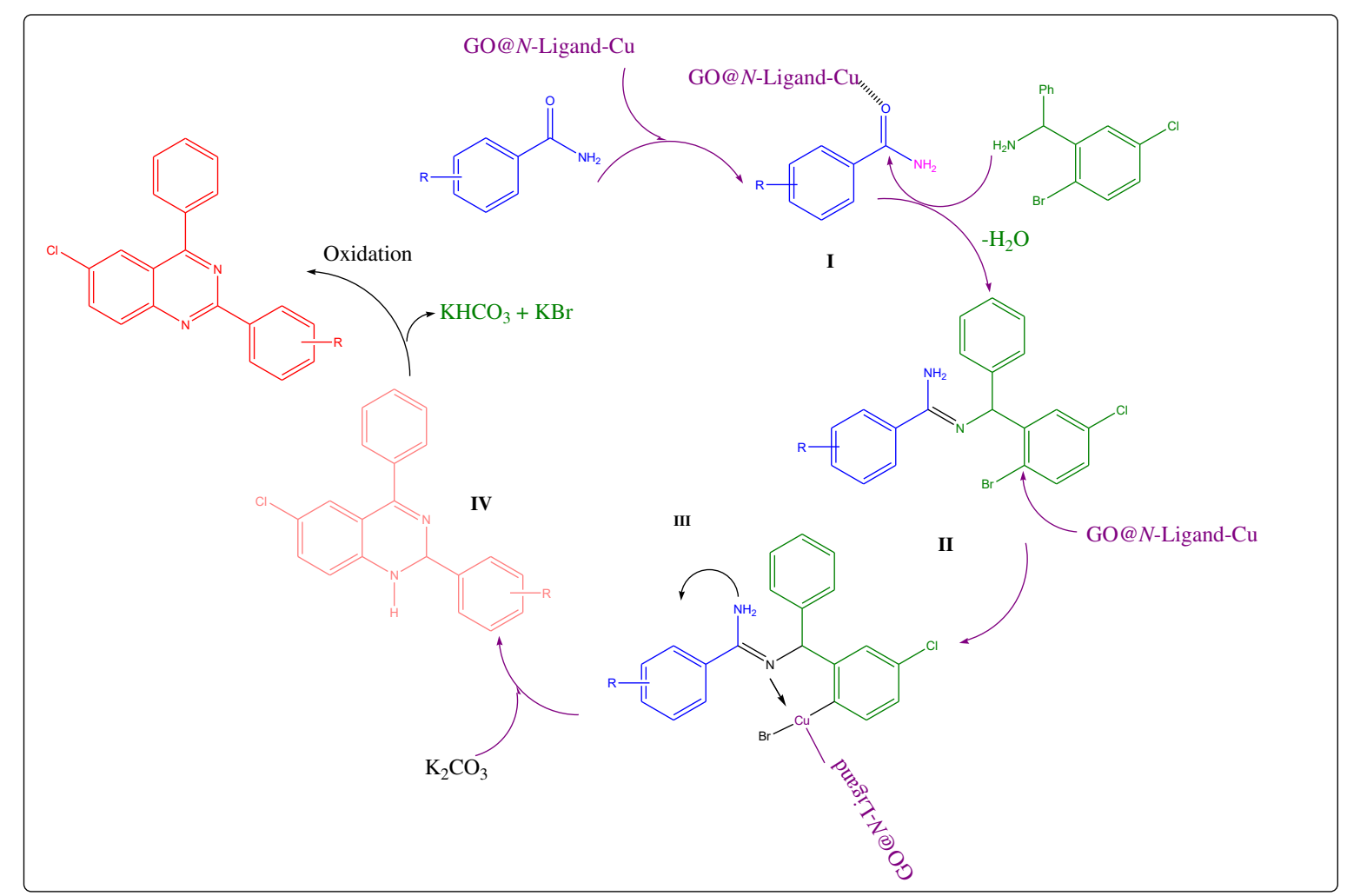

Scheme 5. Proposed mechanism for the synthesis quinazoline by the use of GO@ N-Ligand-Cu and via method 3 (Reaction 3 in Scheme 2)

According to the mechanism proposed, in the first step carbonyl group of amide activated by catalyst (Intermediate I). Then, (2-bromo-5-chlorophenyl)(phenyl)methanamine compound attacks the carbonyl group and form intermediate II. By coupling copper is formed intermediate III. In the next, by cyclization (Intermediate IV) and oxidation is formed quinazoline [38].

In addition to the strategies mentioned, we were able to synthesize quinazoline through another green method, that is a two-component reaction and one-pot of 2-amino-5cholorobenzophenone and benzylamine derivatives (Scheme 2, Reaction 4). During optimization of reaction condition, including temperature, the amount of catalyst and solvents, reaction of 2-amino-5-cholorobenzophenone with 2-(aminomethyl)-6methoxyphenol were used as the model substrate. As shown in Table 6, the reaction had the highest yield at $50{ }^{\circ} \mathrm{C}, 0.005 \mathrm{~g}$ of GO@ $N$-Ligand-Cu in a solvent-free condition and a $\mathrm{O}_{2}$ atmosphere (Entry 1). 


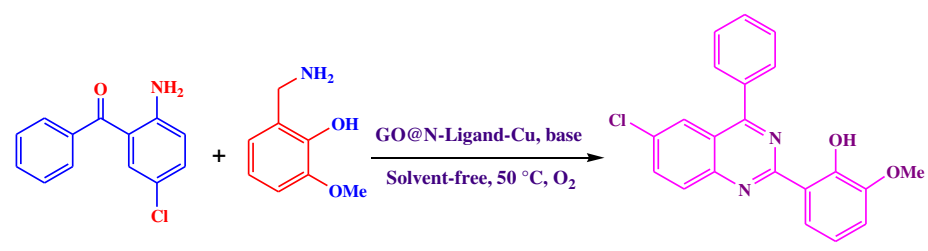

Table 6. Reaction time and yield in various conditions ${ }^{\mathrm{a}}$.

\begin{tabular}{|c|c|c|c|c|c|}
\hline Entery & Solvent & $\begin{array}{c}\text { Amount of catalyst } \\
{[G O @ N \text {-Ligand-Cu (g)] }}\end{array}$ & Temperature $\left({ }^{\circ} \mathbf{C}\right)$ & $\begin{array}{l}\text { Time } \\
(\mathbf{m i n})\end{array}$ & Yield (\%) \\
\hline 1 & Solvent-free & 0.005 & 50 & 20 & 90 \\
\hline 2 & Solvent-free & 0.004 & 50 & 40 & 87 \\
\hline 3 & Solvent-free & 0.003 & 50 & 50 & 80 \\
\hline 4 & Solvent-free & 0.002 & 50 & $1(\mathrm{~h})$ & 60 \\
\hline 5 & Solvent-free & 0.001 & 50 & $4(\mathrm{~h})$ & 35 \\
\hline 6 & Solvent-free & 0.006 & 50 & 30 & 85 \\
\hline 7 & Solvent-free & 0.007 & 50 & 45 & 75 \\
\hline 8 & Solvent-free & 0.008 & 50 & $2(\mathrm{~h})$ & 64 \\
\hline 9 & Solvent-free & 0.005 & 40 & 40 & 80 \\
\hline 10 & Solvent-free & 0.005 & 30 & $1(\mathrm{~h})$ & 71 \\
\hline 11 & Solvent-free & 0.005 & 60 & 25 & 89 \\
\hline 12 & Solvent-free & 0.005 & 70 & 33 & 86 \\
\hline 13 & Solvent-free & 0.005 & 80 & 50 & 74 \\
\hline 14 & $\mathrm{EtOH}$ & 0.005 & 50 & 40 & 75 \\
\hline 15 & $\mathrm{H}_{2} \mathrm{O}$ & 0.005 & 50 & 56 & 67 \\
\hline 16 & $\mathrm{H}_{2} \mathrm{O} / \mathrm{EtOH}$ & 0.005 & 50 & 58 & 72 \\
\hline 17 & Chlorobenzene & 0.005 & 50 & 30 & 84 \\
\hline 18 & Iodobenzene & 0.005 & 50 & $1(\mathrm{~h})$ & 56 \\
\hline 19 & DMSO & 0.005 & 50 & 38 & 69 \\
\hline 20 & Solvent-free & 0.005 & 50 & $5(\mathrm{~h})$ & Trace $^{c}$ \\
\hline 21 & Solvent-free & - & 50 & $24(\mathrm{~h})$ & 5 \\
\hline
\end{tabular}

${ }^{a}$ Reaction condition: 2-amino-5-cholorobenzophenone $(1 \mathrm{mmol})$ and 2-(aminomethyl)-6-methoxyphenol (1 mmol), $50{ }^{\circ} \mathrm{C}, \mathrm{GO} @ N$-Ligand-Cu (0.005 g) and a oxygent atomsphere (Reaction 4, scheme 2). ${ }^{\mathrm{b}}$ Isolated yield. ${ }^{c}$ Under a nitrogen atmosphere. 
A bunch of benzylamines were tested that benzylamine containing electron releasing substituents exhibited the best activity (compare entries 3,10, 15 and 16 in Table 4). We observed to produce a trace amount of the product in the absence of copper nanocatalyst (Table 6, entry 21). We tested a solvent-free condition and many kinds of solvents. It turned out that a solvent-free condition had the highest yield (compare entries 1 and 14-19 in Table 6). The yield decreased when the temperature of reaction was lowered (compare entries 9 and 10 in Table 6). The results are summarized in Tables 4 and 6. A possible mechanism for the synthesis of quinazoline derivatives is proposed in Scheme 6 according to the results above.

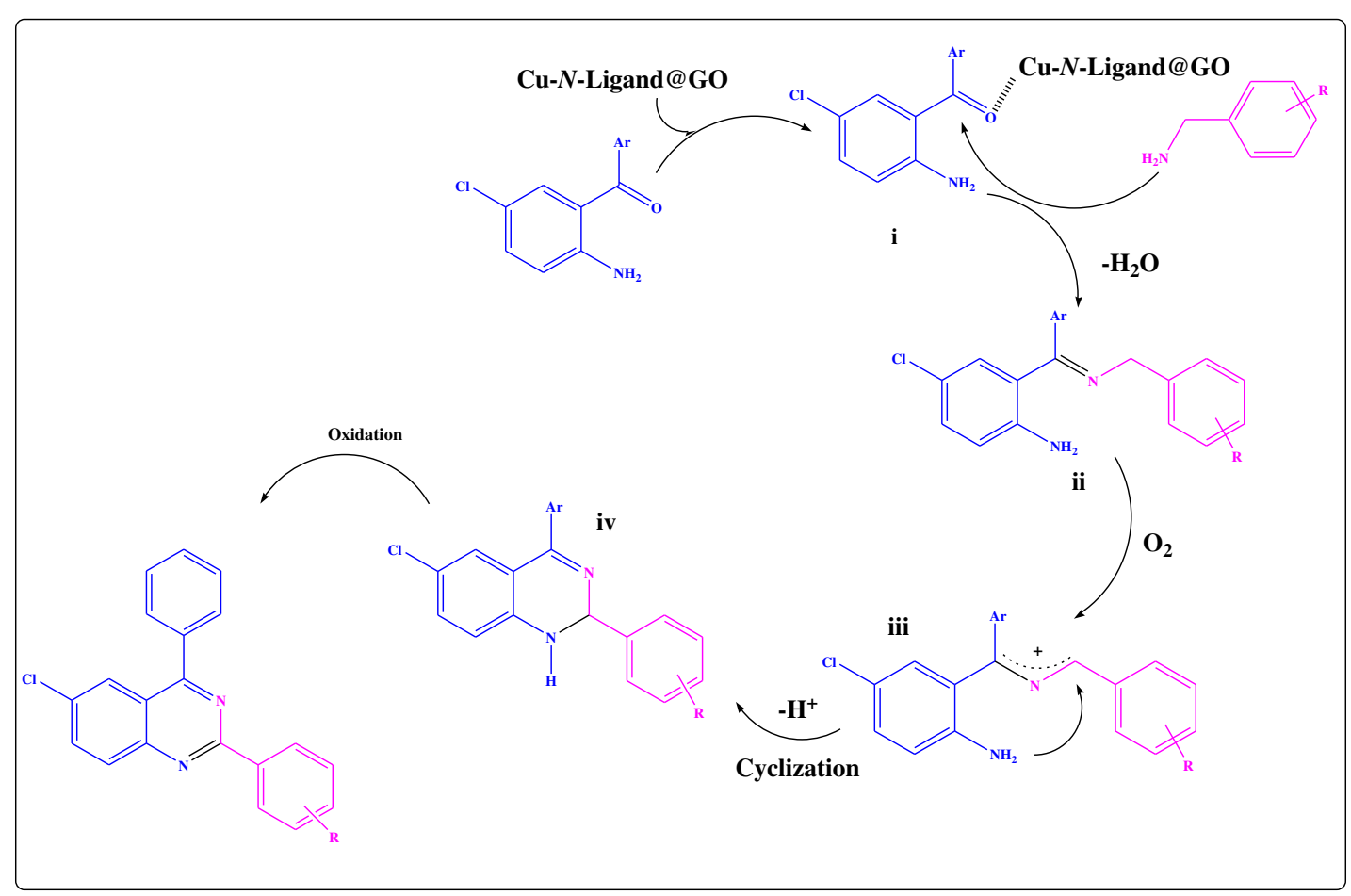

Scheme 6. Proposed mechanism for the synthesis quinazoline by the use of GO@N-Ligand-Cu via method 4 (Reaction 4 in Scheme

Firstly, the group of carbonyl of 2-amino-5-cholorobenzophenone is activated by the GO@N-Ligand-Cu catalyst and forms intermediate i. In the next, after attack of amine, the intermediate ii is formed. Finally, through cyclization, proton loss (intermediate iv) and oxidation quinazoline is produced [39].

Part of our ongoing efforts in the lab for developing new chemical methods for quinazoline synthesis lead to the discovery of a new method was for quinazoline synthesis. To our knowledge, it is the first time that quinazoline is synthesized in this way. In this method, 
quinazoline was synthesized by the one-pot and two-component reaction of 2(amino(phenyl)methyl)-4-chlorobenzeneamine and aldehyde derivatives in the presence of GO@N-Ligand-Cu nanocatalysts (Scheme 2, reaction 5). After checking the effects solvent, temperature, the amount of catalyst and a solvent-free condition in this reaction, we found that the reaction of furan-2-carbaldehyde and 2-(amino(phenyl)methyl)-4-chlorobenzenamine at $75{ }^{\circ} \mathrm{C}$, a solvent-free condition and $0.005 \mathrm{~g}$ of catalyst has a yield $93 \%$ (Table 7 , entry 1 ).

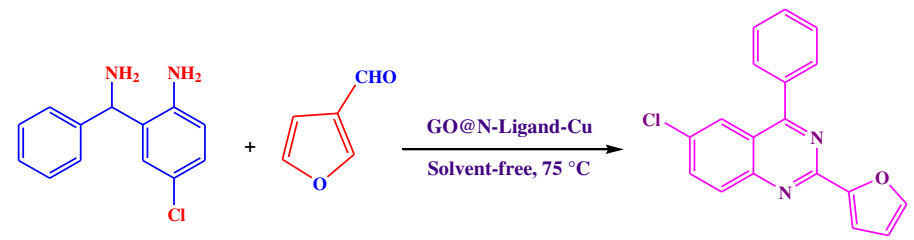

Table 7. Reaction time and yield in various conditions ${ }^{\mathrm{a}}$.

\begin{tabular}{|c|c|c|c|c|c|}
\hline Entery & Solvent & $\begin{array}{c}\text { Amount of catalyst } \\
{[\text { GO@N-Ligand-Cu (g)] }}\end{array}$ & Temperature $\left({ }^{\circ} \mathbf{C}\right)$ & Time (min) & $\operatorname{Yield}(\%)^{\mathrm{b}}$ \\
\hline 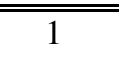 & Solvent-free & 0.005 & $\overline{75}$ & 35 & 93 \\
\hline 2 & Solvent-free & 0.005 & 90 & 30 & 91 \\
\hline 3 & Solvent-free & 0.005 & 115 & 33 & 90 \\
\hline 4 & Solvent-free & 0.005 & 50 & 37 & 87 \\
\hline 5 & Solvent-free & 0.005 & 40 & 45 & 80 \\
\hline 6 & Solvent-free & 0.006 & 75 & 37 & 86 \\
\hline 7 & Solvent-free & 0.007 & 75 & 40 & 82 \\
\hline 8 & Solvent-free & 0.008 & 75 & 55 & 57 \\
\hline 9 & Solvent-free & 0.004 & 75 & 50 & 81 \\
\hline 10 & Solvent-free & 0.002 & 75 & $3(h)$ & 53 \\
\hline 11 & $\mathrm{EtOH}$ & 0.005 & 75 & 45 & 75 \\
\hline 12 & $\mathrm{H}_{2} \mathrm{O}$ & 0.005 & 75 & $2(\mathrm{~h})$ & 40 \\
\hline 13 & Ethanol $/ \mathrm{H}_{2} \mathrm{O}$ & 0.005 & 75 & $1(\mathrm{~h})$ & 50 \\
\hline 14 & Chlofrom & 0.005 & 75 & 40 & 76 \\
\hline 15 & Acetone & 0.005 & 75 & 35 & 78 \\
\hline
\end{tabular}




\begin{tabular}{rccccc}
\hline \hline 16 & Chlorobenzene & 0.005 & 75 & 35 & 83 \\
17 & Iodobenzene & 0.005 & 75 & 1 (h) & 32 \\
18 & Ethyl acetate & 0.005 & 75 & $5(\mathrm{~h} 0$ & 18 \\
19 & Toluene & 0.005 & 75 & $24(\mathrm{~h})$ & 15 \\
\hline
\end{tabular}

${ }^{a}$ Reaction condition: furan-2-carbaldehyde $(1 \mathrm{mmol})$ and 2-(amino(phenyl)methyl)-4-chlorobenzenamine (1 mmol), $75^{\circ} \mathrm{C}$ and GO@N-Ligand-Cu $(0.005 \mathrm{~g})$ (Reaction 5, scheme 2 ). ${ }^{\mathrm{b}}$ Isolated yield.

After this reaction optimization, we studied the various aldehyde derivatives that its results are summarized in Table 4. The aldehydes containing the electron releasing substituents were most effective, especially if they were in the para position (compre entries 1,2,3 with 9 and 10, reaction 5 in the Table 4). Whereas the aldehydes containing the electron-withdrawing substituents were less yield. The mechanism proposed for this reaction is shown in Scheme 7.

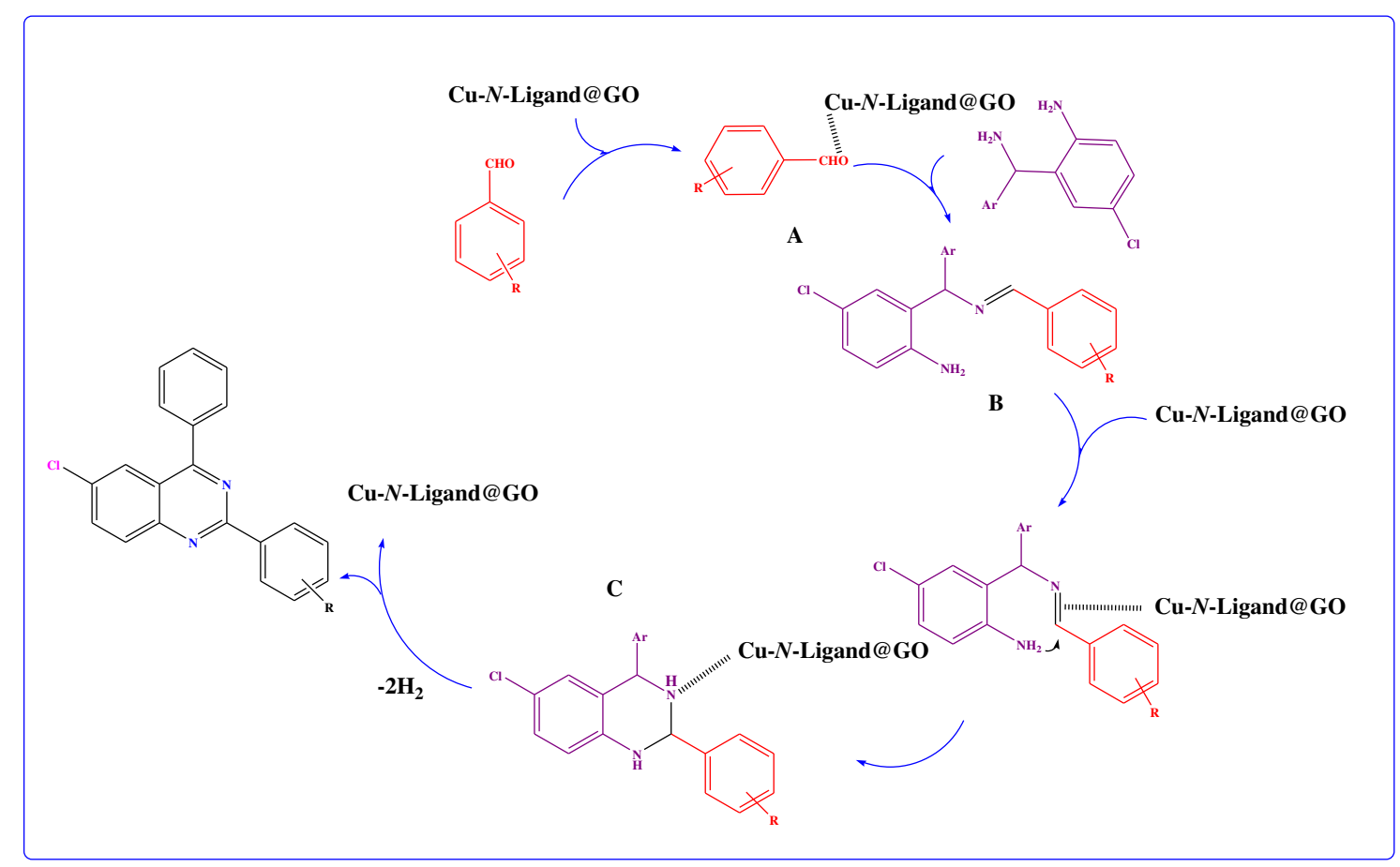

Scheme 7. Proposed mechanism for the synthesis quinazoline by the use of GO@ $N$-Ligand-Cu via method 5 (Reaction 5 in Scheme) 
First, GO@N-Ligand-Cu activate the carbonyl group and forms the intermediate A. Then, amine attacks to carbonyl and creates intermediate B. In the next step, it is achieved by amine attack, ring formation and loss of proton [39].

In another study, to understand the effect of the components used in catalyst synthesis, such as, $N$-Ligand, GO, GO@N-Ligand, $N$-Ligand-Cu and GO@Cu were used separately as catalysts under a optimal condition of the model reactions. The results showed that $N$-Ligand causes thermal stability, retention of graphene sheets to prevent deposition and increases the number of copper atoms used in the manufacture of catalyst. Also, the presence of graphene oxide in the structure of the catalyst as a substrate improves the dispersion of copper metal on the graphene and prevents their accumulation. On the other hand, metal-free catalyst (GO@N-Ligand) due to reduced catalytic activity in reaction and poisoning by intermediate compounds convinced us to use metal. The results are summarized in Table 8 .

Table 8. Model reaction under different catalysts

\begin{tabular}{c|c|c|c|c|c|c|}
\hline \hline Entry & Catalyst & $\begin{array}{c}\text { Yield (\%) } \\
\text { Reaction 1 }\end{array}$ & $\begin{array}{c}\text { Yield (\%) } \\
\text { Reaction 2 }\end{array}$ & $\begin{array}{c}\text { Yield (\%) } \\
\text { Reaction 3 }\end{array}$ & $\begin{array}{c}\text { Yield (\%) } \\
\text { Reaction 4 }\end{array}$ & $\begin{array}{c}\text { Yield (\%) } \\
\text { Reaction 5 }\end{array}$ \\
\hline \hline 1 & - & 9 & - & - & 8 & 6 \\
\hline 2 & $N$-Ligand & 9 & - & - & 8 & 7 \\
\hline 3 & GO & 22 & - & - & 25 & 35 \\
\hline 5 & GO/Cu & 46 & 58 & 44 & 57 & 10 \\
\hline 6 & $N$-Ligand/Cu & 15 & 23 & 20 & 90 & 93 \\
\hline
\end{tabular}

\section{Bis-Quinazoline}

Nitrogen-rich heterocyclic compounds represent a unique class of chemicals with special properties and have been modified to design novel pharmaceutically active compounds. Bisquinazoline is considered a premium structure in pharmaceutical chemistry. Since they have several active centers, they have a high affinity to connect to pathogens. That is why, Their 
mechanism of action is extraordinary. Given this feature, the trend of using bis-quinazoline in the structure of drugs has been increasing in recent years. Figure 11 is an example of the structure of bis-quinazoline used in most sedatives.

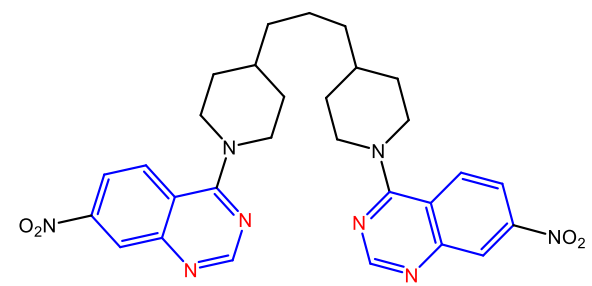

Figure 11. 1-(7-nitroquinazoline)-4-(3-(1-methylpiperidin-4-yl)propyl)piperidine

So far various methods have been reported to synthesize them, each having disadvantages such as solvent utilization, reaction time, low yield and so on. In this paper, we reported a green effective method for their synthesis (Scheme 8). In which using a one-step reaction of (2-amino-5-chlorophenyl)benzophenone and 1-(3-phenoxypropoxy)benzaldehayde in the presence of $0.009 \mathrm{~g}$ nanocatalysts at $85{ }^{\circ} \mathrm{C}$ and a solvent-free condition bis-quinazoline was achieved.

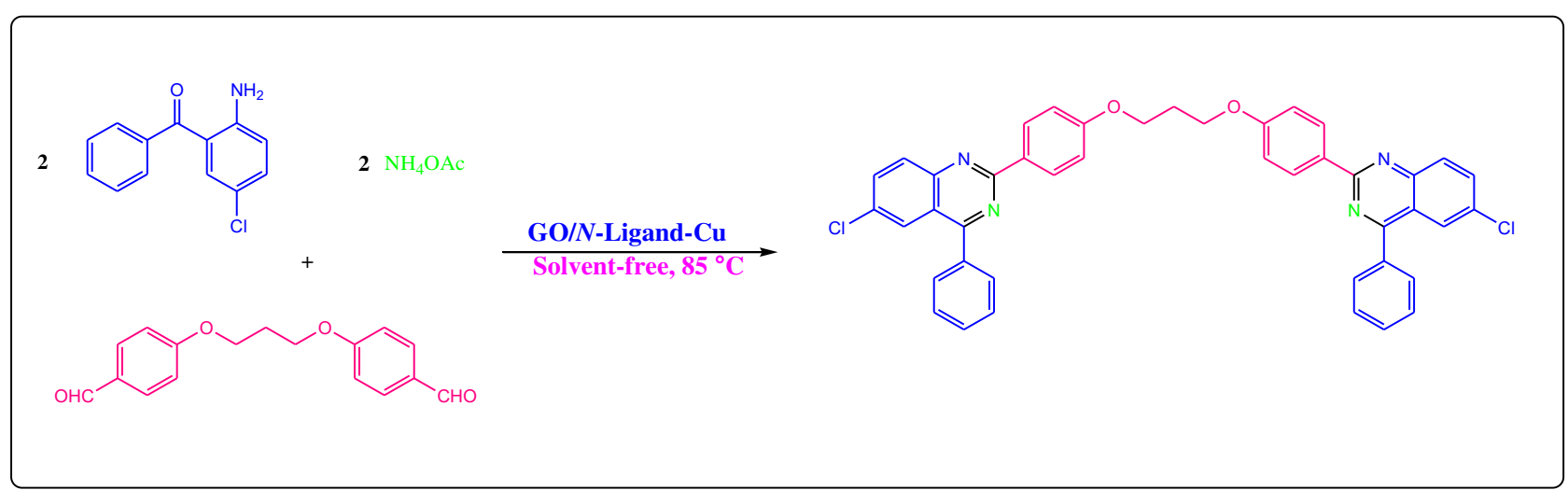

Scheme 8. Synthesis of bis-quinazoline.

The proposed mechanism for the synthesis of bis-quinazoline is presented in Scheme 9. The compound 1-(3-phenoxypropoxy)benzaldehayde has two carbonyl groups, that are activated by the catalyst copper atoms simultaneously (intermediate 1). In the following, amine groups of 2-amino-5-chlorobenzophenone attack to activated carbonyls (intermediate 
2). Next, carbonyls of intermediate 2 are activated by the catalyst. Then, ammonia attacks the actived carbonyls and forms the intermediate 3. Finally, it is obtained bis-quinazoline by the intramolecular reaction and oxidation [8].

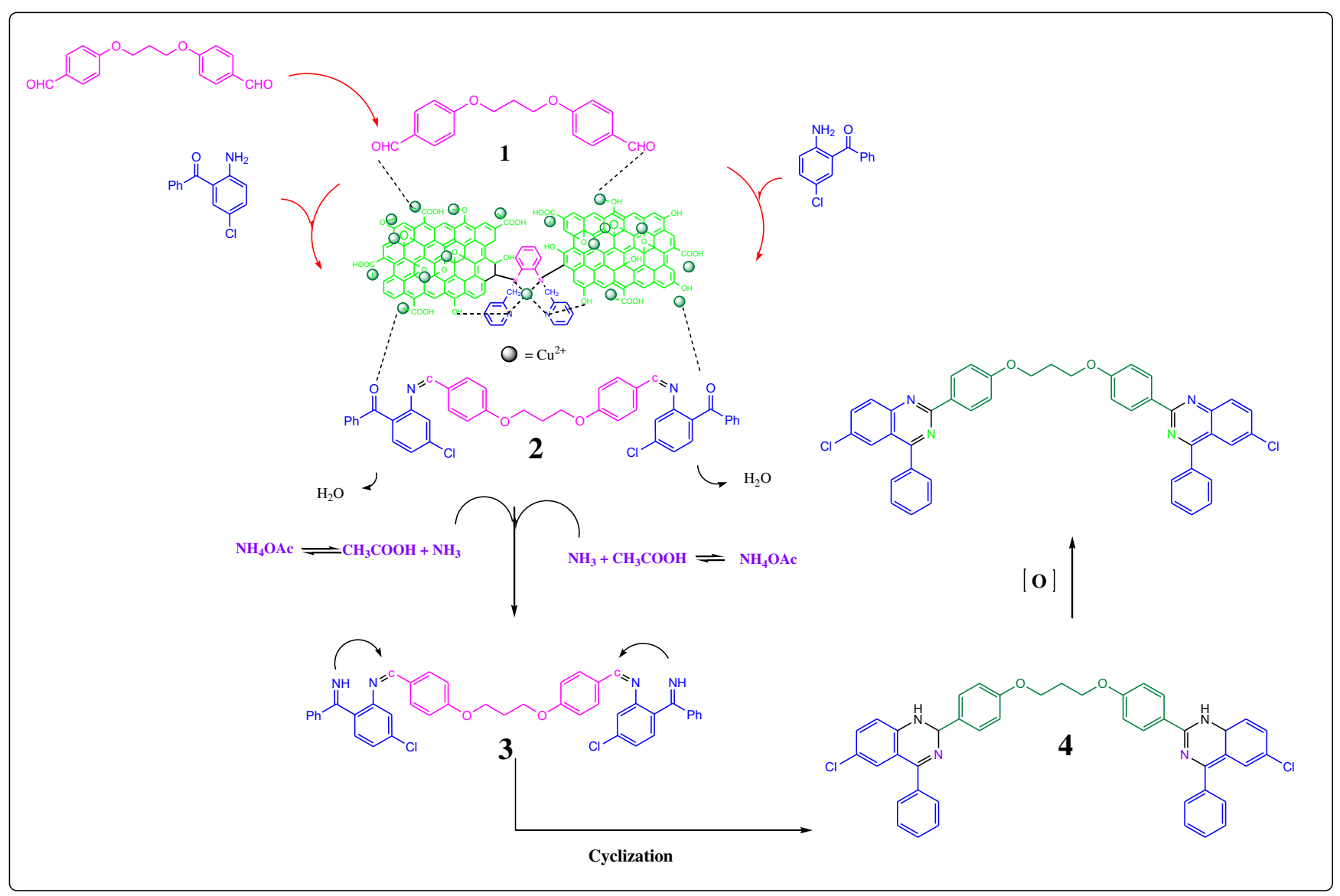

Scheme 9. Proposed mechanism for the synthesis bis-quinazoline using GO@ N-Ligand-Cu

\section{Conclusion}

There have been many attempts over the past few decades to synthesize $N$-heterocycles. Every year, different ways of synthesizing them are offered around the world. In this article, we have synthesized a couple of green protocols for the synthesis of biological derivatives of quinazoline and bis-quinazoline. The main advantages of these methods are outlined as very simple, reliable, applicable, easy reaction workup, easy recyclability, and reusability of the catalyst. The synthesized catalyst and products were characterized by FE-SEM, MASS, HNMR, C-NMR, TGA, XRD and FT-IR techniques. We have developed successfully a new approach toward the synthesis of quinazoline and bis-quinazoline. 


\section{Acknowledgements}

The authors wish to thank Bu-Ali Sina University, Center of Excellence Developmental of Environmentally Friendly Methods for Chemical Synthesis (CEDEFMCS) for financial support to carry out this research.

\section{References}

[1] N. Shchepina, V. Avrorin, G. Badun, S. Shurov, R. Shchepin, Chemical effects of nuclear transformations and possible formation of unknown derivatives with $\mathrm{N}$ phenylquinazolinium structure, Radiochim. Acta. 108, 105-111 (2020).

[2] D. Deshmukh, M. Bhalchandra, Molecular iodine catalysed benzylic sp3 C-H bond amination for the synthesis of 2-arylquinazolines from 2-aminobenzaldehydes, 2aminobenzophenones and 2-aminobenzyl alcohols, Synlett. 29, 979-985 (2018).

[3] M. Krapf, J. Gallus, A. Spindler, M. Wiese, Synthesis and biological evaluation of quinazoline derivatives-A SAR study of novel inhibitors of ABCG2, Eur. J. Med. Chem. 161, 506-525 (2019).

[4] R. S. M. Ismail, N. S. M. Ismail, S. Abuserii, D. A. Ella, Recent advances in 4aminoquinazoline based scaffold derivatives targeting EGFR kinases as anticancer agents, Future J. Pharm. Sci. 2, 9-19 (2016).

[5] Ch. Yu, X. Guo, Zh. Xi, M. Muzzio, Zh. Yin, B. Shen, J. Li, Ch. T. Seto, Sh. Sun, AgPd nanoparticles deposited on WO2. 72 nanorods as an efficient catalyst for one-pot conversion of nitrophenol/nitroacetophenone into benzoxazole/quinazoline, J. Am. Chem. Soc. 139, 5712-5715 (2017).

[6] I. Khan, A. Ibrar, W. Ahmed, A. Saeed, Synthetic approaches, functionalization and therapeutic potential of quinazoline and quinazolinone skeletons: the advances continue, Eur. J. Med. Chem. 90, 124-169 (2015).

[8] R. Ghorbani-Vaghei, M. Shirzadi-Ahodashti, F. Eslami, S. M. Malaekehpoor, Z. Salimi, Z. Toghraei-Semiromi, S. Noori, Efficient One-Pot Synthesis of Quinazoline and Benzopyrano [2, 3-d] pyrimidine Derivatives Catalyzed by N-Bromosulfonamides, J. Heterocycl. Chem. 54, 215-225 (2017).

[9] S. Muralikrishna, S. Cheunkar, B. Lertanantawong, T. Ramakrishnappa, D. H. Nagaraju, W, Surareungchai, R. G. Balakrishna, K. R. Reddy, Graphene oxide-Cu (II) composite 
electrode for non-enzymatic determination of hydrogen peroxide, J. Electroanalytical Chem. 776, 59-65 (2016).

[10] S. Babaee, M. A. Zolfigol, 1, 10-Phenanthroline-Based Molten Salt as a Bifunctional Sulfonic Acid Catalyst: Application to the Synthesis of $N$-Heterocycle Compounds via Anomeric Based Oxidation, Chemistryselect. 3, 8947-8954 (2018).

[11] A. Safinaz, F. Barsoum, H. Georgey, E. R. Mohammed, Synthesis and antitumor activity of certain 2, 3, 6-trisubstituted quinazolin-4(3H)-one derivatives, Cairo university, 51, 273-282 (2013).

[12] T. Olomola, DA. Akinpelu, CA. Obafemi, Microwave-assisted synthesis and antibacterial activity of some quinazolinone derivatives, J. Pharm. Pract. Res. 6, 633-637 (2013).

[13] W. L. F. Armarego, Quinazoline Based Synthesis of some Heterocyclic Schiff Bases. In Quinazolinone and Quinazoline Derivatives, IntechOpen. 107 (2020).

[14] R. Rajput, A. P. Mishra, A review on biological activity of quinazolinones, Int. J. Pharm. Sci. 4, 66-70 (2012).

[15] B. Pati, S. Banerjee, Quinazolines: an illustrated review, J. Adv. Pharm. Educ. Res. 3, 136-151 (2013).

[16] B. Vijayakumar, P. Prasanthi, K. M. Teja, Quinazoline derivatives and pharmacological activities: a review, Int J Med Chem, 3, 10-21 (2013).

[17] M. Asif, A mini review on antimalarial activities of biologically active substituted triazoles derivatives, J. Med. Chem. (2014).

[18] S. K. Panja, N. Dwivedi, S. Saha, Tetrahedron Lett. 53, 61-67 (2012).

[19] K. A. Espinoza1, J. R. Rodriguez, R. M. Felix, J. M. Cornejo-Bravo, I. A. Rivero1, Synthesis and Electrochemistry Evaluation of Multivalent o-Aminobenzamides and Quinazoline-2, 4-diones, Int. J.Electrochem. Sci. 13, 832-841 (2018).

[20] K. Das, A. M. Pal, D. Srimani, Sustainable synthesis of quinazoline and 2aminoquinoline via dehydrogenative coupling of 2-aminobenzyl alcohol and nitrile catalyzed by phosphine-free manganese pincer complex, Org. Lett. 21.9, 3223-3227 (2019). 
[21] M. Movassaghi, M. D. Hill, Single-step synthesis of pyrimidine derivatives, J. Am. Chem. Soc. 128, 14254-14255 (2006).

[23] A. G. Myers, N. J. Tom, M. E. Fraley, S. B. Cohen, D. J. Madar, A convergent synthetic route to (+)-dynemicin A and analogs of wide structural variability, J. Am. Chem. Soc. 119, 6072-6094 (1997).

[24] R. Nanthakumar, P. Muthumani, K. Girija, Anti-inflammatory and antibacterial activity study of some novel quinazolinones, Arab. J. Chem. 7, 1049-1054 (2014).

[25] Zh. Chen, J. Chen, M. Liu, J. Ding, W. Gao, X. Huang, H. Wu, Unexpected coppercatalyzed cascade synthesis of quinazoline derivatives, J. Org. Chem. 78, 11342-11348 (2013).

[26] K, Waisser, J. Gregor, H. Dostal, J. Kunes, L. Kubicova, V. Klimesova, J. Kaustova, Influence of the replacement of the oxo function with the thioxo group on the antimycobacterial activity of 3-aryl-6,8-dichloro-2 $H$-1,3-benzoxazine-2,4(3H)-diones and 3-arylquinazoline-2, 4 (1H, 3H)-diones, Il Farmaco, 56, 803-807 (2001).

[27] M. A. McGowan, C. Z. McAvoy, S. L. Buchwald, Palladium-catalyzed N-monoarylation of amidines and a one-pot synthesis of quinazoline derivatives, Org. Lett. 14, 3800-3803 (2012).

[28] J. J. Marugan, W. Zheng, O. Motabar, Nouthall, E. Goldin, W. Westbroek, B. K. Stubblefield, E. Sidransky, R. A. Aungst, W. A. Lea, A. Simeonov, W. Leister, Ch. P. Austin, Evaluation of quinazoline analogues as glucocerebrosidase inhibitors with chaperone activity, J. Med. Chem. 54, 1033-1058 (2011).

[29] A. Mishra, V. K. Singh, T. Mohanty, Coexistence of interfacial stress and charge transfer in graphene oxide based magnetic nanocomposites, arXiv preprint arXiv. 52, 7677-7687 (2017).

[30] R. Ghadari, H, Namazi, M. Aghazadeh, Synthesis of graphene oxide supported coppercobalt ferrite material functionalized by arginine amino acid as a new high-performance catalyst, Appl. Organomet. Chem. 32, e3965 (2018).

[30] Y. You-Yia, ZH. Heng-Qiang, Reduced Graphene Oxide Coupled Magnetic $\mathrm{CuFe}_{2} \mathrm{O}_{4}-$ $\mathrm{TiO}_{2}$ Nanoparticles with Enhanced Photocatalytic Activity for Methylene Blue Degradation, Chinese J. Struct. Chem. 35, 472-480 (2016). 
[31] Z. Karamshahi, R. Ghorbani-Vaghei, N. Sarmast, Efficient synthesis of multiply substituted $7 H$-indeno[2,1-c] quinoline using 7-aminonaphthalene-1, 3-disulfonic acid supported on LDHs as catalyst, Mater. Sci. eng. 97, 45-54 (2019).

[32] Y. Fu, Q. Chen, M. He, Y. Wan, X. Sun, H. Xia, X. Wang, Copper ferrite-graphene hybrid: a multifunctional heteroarchitecture for photocatalysis and energy storage, Ind. Eng. Chem. Res. 51, 11700-1170 (2012).

[33] A. Gupta, R. Jamatia, R. A. Patil, Y. Ma, A. K. Pal, Copper oxide/reduced graphene oxide nanocomposite-catalyzed synthesis of flavanones and flavanones with triazole hybrid molecules in one pot: a green and sustainable approach, ACS Omega. 3, 7288-7299 (2018).

[34] Y.T. Xi, a. P. J. Wei, R. Ch. Wang, J. G. Liu, ChemComm. 51, 7455-7458 (2015).

[35] Y. Ouyang, X. Caib, Q. Shia, L. Liua, D. Wanb, Sh. Tanb,Y. Ouyang, Poly-l-lysinemodified reduced graphene oxide stabilizes the copper nanoparticles with higher watersolubility and long-term additively antibacterial activity, Colloids Surf. 107, 107-114 (2013).

[36] A. Emami-Nori, Z. Karamshahi, R. Ghorbani-Vaghei, Efficient Synthesis of Multiply Substituted Triazines Using GO@N-Ligand-Cu Nano-Composite as a Novel Catalyst, J Inorg Organomet Polymer Mater. (2020).

[37] P. Molina, M. Alajarín, A. Vidal, New methodology for the preparation of quinazoline derivatives via tandem Aza-Wittig/heterocumulene-mediated annulation. Synthesis of 4 (3H)-quinazolinones, benzimidazo [1,2-c] quinazolines, quinazolino [3,2- $a$ ] quinazolines and benzothiazolo [3,2-c] quinazolines, Tetrahedron, 45, 4263-4286 (1989).

[38] C. Xu, F. C. Jia, Z. W. Zhou, S. J. Zheng, H. Li, A. X. Wu, Copper-catalyzed multicomponent domino reaction of 2-bromoaldehydes, benzylamines, and sodium azide for the assembly of quinazoline derivatives, J. Org. Chem. 81, 3000-3006 (2016).

[39] C. Wang, S. Li, H. Liu, Y. Jiang, H. Fu, Copper-catalyzed synthesis of quinazoline derivatives via ullmann-type coupling and aerobic oxidation, J. Org. Chem. 75, 79367938 (2010). 


\section{Supplementary Files}

This is a list of supplementary files associated with this preprint. Click to download.

- GraphicalAbstract.doc

- ResearchHighlights.doc

- ElectronicSupplementaryInformation1.docx

- ElectronicSupplementaryInformation2.doc

- ElectronicSupplementaryInformation3.doc 